\title{
Effect of heat treatment on corrosion behavior of AZ63 magnesium alloy in 3.5 wt.\%
}

\author{
sodium chloride solution
}

Jiarun Li ${ }^{1,2}$, Quantong Jiang ${ }^{1}$, Huyuan Sun ${ }^{* 1}$, Yantao Li ${ }^{* 1}$

1. Key Laboratory of Marine Environmental Corrosion and Bio-fouling, Institute of

Oceanology, Chinese Academy of Sciences, Qingdao 266071, China;

2. University of Chinese Academy of Sciences, Beijing 100049, China

Abstract: The as-cast, homogenized, and peak-aged AZ63 alloys are investigated via microstructure observation, EDS analysis, hydrogen evolution, and electrochemical tests. The results suggest that the heat treatments exert an influence on the corrosion behavior of AZ63 alloy via the microstructure transformation. The corrosion of homogenized alloy is retarded by protective oxide layer at first, but achieves highest corrosion rate among the three alloys owing to the less protective products film. The micro-galvanic couples endow the as-cast and peak-aged alloys high dissolution activity, but the adhesive products alleviate the corrosion. Two models are proposed to interpret the dissolution mechanism for these alloys.

Keywords: Magnesium; Alloy; EIS; Modeling studies

\section{Introduction}

Magnesium alloys are useful structural materials due to their high strength to weight ratio, low density, and good castability [1]. However, poor corrosion resistance limits their usages in aerospace and automotive fields [2]. As a consequence, considerable works have been conducted to understand the principles of corrosion for magnesium, and to improve the corrosion resistance by the design and development of new alloys, inhibitors, and coatings [3-8]. Meanwhile, magnesium alloys are

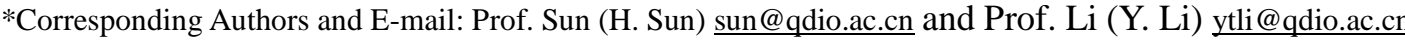
Address: Nanhai Road 7, Qingdao, China. Telephone number: +86-532-82898732 
also an ideal anode material for numerous applications, especial for cathodic protection and seawater activated battery fields [9-11], due to the favorable electrochemical characteristics of magnesium, such as a relatively negative electrode potential $(-2.37 \mathrm{~V}$ versus a standard hydrogen electrode (SHE)) and high faradic capacity (2189 $\left.\mathrm{A} \mathrm{h} \mathrm{kg}^{-1}\right)$. However, some disadvantages of magnesium alloys (e.g., the adhesion of corrosion products and hydrogen evolution with anodic polarization) seriously limit the development of magnesium alloys as anode materials. Hence, studies for improving anode performance have also been conducted. It is generally recognized that doping with minor alloying elements (e.g., aluminum, zinc, gallium, indium, manganese, and mercury [12-14]) optimizes anode performance via facilitating the self-peeling of corrosion products and alleviating self-discharge $[15,16]$. Therefore, a fundamental understanding of the corrosion characteristics of magnesium alloys independent of the individual applications considered should be clearly outlined as a basis for further investigations.

$\mathrm{Mg}-\mathrm{Al}-\mathrm{Zn}$ alloys are important materials in numerous industrial fields, and their corrosion behaviors have been the subject to numerous investigations, particularly for the AZ91 alloy [17-24]. It is generally recognized that the microstructure, especially for the precipitation of the $\beta-\mathrm{Mg}_{17} \mathrm{Al}_{12}$ phase on the grain boundaries along the $\alpha-\mathrm{Mg}$ grain, where the $\beta-\mathrm{Mg}_{17} \mathrm{Al}_{12}$ phase acts as either a galvanic cathode or anodic dissolution barrier depending on its volume fraction and distribution in the matrix [18-20,22, 25], has a significant influence on the corrosion behavior of Mg-Al-Zn alloys.

AZ63 alloy with nominal composition of $6 \mathrm{wt} . \% \mathrm{Al}$ and $3 \mathrm{wt} . \% \mathrm{Zn}$, is one of the widely used magnesium alloy that serves as both structural and anode material due to its favorable mechanical and electrochemical properties [26, 27]. Unfortunately, the investigations for AZ63 alloy are not as through as that of AZ91 alloy. Several studies have concentrated on the relationship between the 
microstructure and mechanical properties. Zhang et al. [28] doped lower content (less than 0.9 wt.\%) of Ca to AZ63 magnesium alloy and found that the Ca distributed unevenly both in matrix and in compound phase. Nevertheless, the addition of lower $\mathrm{Ca}$ could refine the grain and improve the mechanical properties via improving the $\beta-\mathrm{Mg}_{17} \mathrm{Al}_{12}$ phase uniform distribution. Qian et al. [29] discussed the effects of $\mathrm{Ca}(0.15 \mathrm{wt} . \%, 0.75 \mathrm{wt} . \%$ and $1.5 \mathrm{wt} . \%)$ on microstructure and properties of AZ63 alloys. They also stress that the Ca addition plays a grain refinement role on the microstructure but excessive addition (1.5 wt. \%) might coarsen the grains inversely. Besides, they found that the ignition temperatures increase with increasing melt viscosities. Chen et al. [30,31] investigated the impact factors on microstructure and tensile properties of thixoforged AZ63 magnesium alloys. The results suggested that the mould temperature affected the solidification behavior, plastic deformation and recrystallization during thixoforging by changing solidification rate. $\mathrm{MgCO}_{3}$ refiner affected the morphology and $\alpha-\mathrm{Mg}$ grain size through altering the $\mathrm{Al}$ content of liquid phase. High mould temperature and refiner concentration were beneficial for obtaining a compact microstructure with uniform deformation, and thus, the tensile properties were improved consequently. The effects of the reheating temperature on liquid fraction and liquid composition of semisolid ingot, and thus the subsequent solidification behaviour and plastic deformation during thixoforging, are larger than those of the reheating time.

At the same time, the microstructures correlated to electrochemical behaviors of AZ63 alloy is also an important subject for investigations. However, very little work has been committed to this field. The correlation between the microstructure and the electrochemical behavior of AZ63 alloy in as-cast and homogenized states after immersion for $1 \mathrm{~h}$ in $\mathrm{H}_{3} \mathrm{PO}_{4} / \mathrm{KOH}$ buffered $\mathrm{K}_{2} \mathrm{SO}_{4}$ solution was reported in the work of Anik et al. [26], suggesting that both the galvanic interactions between 
the microstructural constituents and the stability of the partially protective oxide layer determine the corrosion characteristics of AZ63 alloy. Besides, they proposed that the oxide film on homogenized AZ63 alloy was estimated sustained and protective. The influence of hybrid solution and aging treatments on the degradation of die-cast AZ63 alloy in simulated body fluid was reported in the work of Liu et al. [32], where it proposed that the aging treatment enhanced the corrosion resistance of the alloy, and the lowest corrosion rate achieved for the aged sample was approximately one-half of the untreated alloy. The prolonged aging time improved the corrosion resistance via forming a more continuous microstructure of $\beta-\mathrm{Mg}_{17} \mathrm{Al}_{12}$ phase acting as barriers for corrosion. The effects of the chloride ion concentration and $\mathrm{pH}$ on the corrosion and electrochemical behavior of as-cast AZ63 alloy were reported in the work of Altun and Sen [27], revealing that the corrosion rates usually increase with decreasing $\mathrm{pH}$ and increasing chloride ion concentration. Jarafi and Amiryavari [33] investigated the effects of zirconium and beryllium on microstructure evolution, mechanical properties and corrosion behavior of as-cast AZ63 alloy in $3.5 \mathrm{wt} . \% \mathrm{NaCl}$ saturated with $\mathrm{Mg}(\mathrm{OH})_{2}$, the results revealed that the $\mathrm{Zr}$ addition refined grains via forming the compound $\mathrm{Al}_{2} \mathrm{Zr}$, which promoted the corrosion resistance due to the microstructure modification and passivation effects. However, the studies mentioned above ignored the variations in the corrosion mechanism under extended immersion periods, which could be expected to lead to misunderstandings regarding to the corrosion rate. Thus, it is important from a practical viewpoint to evaluate the corrosion mechanism of AZ63 alloy with respect to different precipitates and surface states for both structural and electrochemical applications.

\section{Experimental methods}

\subsection{Materials}


Magnesium alloy AZ63 with a nominal composition of Mg-6 wt.\% Al-3 wt.\% Zn-0.3 wt.\% Mn was prepared by melting together pure $\mathrm{Mg}, \mathrm{Al}$, and $\mathrm{Zn}$, and $\mathrm{Mg}-\mathrm{Mn}$ (30 wt.\%) ingots in a resistance furnace at $720^{\circ} \mathrm{C}$. The molten metals protected by sulfur powder were poured into preheated (220 $\left.{ }^{\circ} \mathrm{C}\right)$ steel molds with a dimension of $\phi 300 \times 50 \mathrm{~mm}$, and then cooled by water. The actual chemical composition of the as-cast alloy analyzed by inductively coupled plasma mass spectrometry (ICPMS) was 5.683 wt.\% Al, 2.681 wt.\% Zn, and 0.301 wt.\% Mn with the remainder Mg. The alloys were subsequently subjected to the thermal processes listed in Table 1, where the homogenized and peak-aged samples were henceforth denoted as T4 and T5 samples.

\subsection{Materials characterization}

For metallographic observation, samples were ground to 2000 grit successively, polished with diamond grinding paste, and then etched with $4 \%$ nital solution (nitric acid in ethanol) for $3 \mathrm{~s}$ to reveal the secondary phase and grain boundaries.

The metallographic morphologies and corroded surfaces were observed by scanning electron microscopy (SEM; JSF-6700F) equipped with energy dispersive X-ray spectroscopy (EDS; INCA, Oxford Instruments). The phase of the matrix and corrosion products were determined by X-ray diffraction (XRD; D/Max 2550, Rigaku) with $\mathrm{Cu} \mathrm{K \alpha}$ radiation.

\subsection{Gas collection}

For gas collection, $1 \mathrm{~cm} \times 5 \mathrm{~cm} \times 0.5 \mathrm{~cm}$ samples were prepared and weighed, and then sealed by insulating tape leaving a $5 \mathrm{~cm}^{2}$ exposed surface. Funnels were inverted on the samples to transfer the generated hydrogen bubbles into burets during the course of immersion [11]. The corrosion products after immersion tests were observed by SEM, and then removed by a chromic acid solution. Finally, the samples were washed with deionized water, dried by cold air flow, and reweighed by 
analytical balance.

\subsection{Electrochemical measurements}

Samples for electrochemical testing were $10 \mathrm{~mm} \times 10 \mathrm{~mm} \times 10 \mathrm{~mm}$ cubes. Prior to conducting the electrochemical tests, the electrodes were encapsulated in epoxy resin leaving a $10 \mathrm{~mm} \times 10 \mathrm{~mm}$ surface, ground to 2000 grit successively by SiC emery paper, degreased by ethanol, and dried by cold flowing air. The electrolyte was $3.5 \mathrm{wt} . \% \mathrm{NaCl}$ (comprised of A.R. sodium chloride and deionized water) at $25 \pm 1{ }^{\circ} \mathrm{C}$.

An electrochemical workstation (Reference 3000, Gamry Instruments, Inc.) was employed in a three-electrode configuration with $450 \mathrm{~mL}$ electrolyte for obtaining the half-cell characterization of the experimental alloys. A platinum foil $(20 \mathrm{~mm} \times 20 \mathrm{~mm} \times 3 \mathrm{~mm})$ and saturated calomel electrode (SCE) acted as counter electrode and reference electrode respectively. Potentiodynamic polarization curves were obtained at a scanning rate of $0.333 \mathrm{mV} / \mathrm{s}$. Electrochemical impedance spectroscopy (EIS) tests at free corrosion potential were conducted at different immersion times $(10 \mathrm{~min}, 1 \mathrm{~h}, 12$ $\mathrm{h}$, and $24 \mathrm{~h}$ ). The perturbation signal had an $\mathrm{AC}$ amplitude of $5 \mathrm{mV}$ and a frequency range from $100 \mathrm{kHz}$ to $10 \mathrm{mHz}$. Mott-Schottky measurements for recording capacitance-voltage profiles employed a $5 \mathrm{mV}$ AC perturbation signal at a constant frequency of $1 \mathrm{kHz}$ with a variable anodic potential from 0 to $300 \mathrm{mV}$ versus free corrosion potential. In this manuscript, if not specified, all potentials were given with respect to the SCE. The measurements of section 2.3 and 2.4 mentioned above were duplicated at least three times to confirm good reproducibility.

\section{Results and Discussion}

\subsection{Microstructure of AZ63 Magnesium Alloys}

Fig. 1 presents SEM images of the AZ63 alloys for different heat treatment conditions. The 
microstructure of the T4 alloy shown in Fig. 1(b) is consisted of a single $\alpha-\mathrm{Mg}$ phase with some precipitates in the matrix. The as-cast and T5 alloys shown in Figs. 1(a) and (c), respectively, exhibit similar microstructure consisted of $\alpha-\mathrm{Mg}$ surrounded with precipitates along grain boundaries and some precipitates in the $\alpha-\mathrm{Mg}$ matrix. The fraction of precipitates in the alloys could be ranked as: T4 < as-cast $<$ T5. The amplified microstructure of the T5 alloy shown in Fig. 1(d) indicates that the $\beta$ phase is surrounded by a eutectic $\alpha$ phase, which is consistent with the description of Song et al. [19]

The XRD patterns of the AZ63 alloys shown in Fig. 2 indicate that $\alpha-\mathrm{Mg}$ is the major phase in the alloys considered, and the second phase of the as-cast and T5 alloys is $\mathrm{Mg}_{17} \mathrm{Al}_{12}$. The $\beta-\mathrm{Mg}_{17} \mathrm{Al}_{12}$ peak is not detected in the $\mathrm{T} 4$ alloy, implying that the alloying element $\mathrm{Al}$ has been dissolved into the $\mathrm{Mg}$ matrix by homogenization [34]. The intensity of the $\mathrm{Mg}_{17} \mathrm{Al}_{12}$ peaks observed in Fig. 2(c) are higher than those of in Fig. 2(a), indicating that the T5 treatment promotes the precipitation of the $\beta-\mathrm{Mg}_{17} \mathrm{Al}_{12}$ phase via maintaining the temperature below solidus for a certain period. This is supported by the SEM images of the metallographic structure shown in Fig. 1.

Fig. 3 presents the SEM image of the as-cast alloy and its corresponding elemental distributions of $\mathrm{Mg}, \mathrm{Al}$, and $\mathrm{Zn}$. Mg distributes homogeneously in the $\alpha-\mathrm{Mg}$ grains (Fig. 3(b)), whereas $\mathrm{Al}$ concentrates both on grain boundaries and in precipitates in $\alpha-\mathrm{Mg}$ matrix (Fig. 3(c)). In comparison, Zn distributes homogeneously (see Fig. 3(d)). That Mn is not detected probably due to its low concentration in the matrix.

The EDS results of the $\alpha-\mathrm{Mg}$, grain boundaries, and precipitates of as-cast, T4, and T5 alloys like those regions marked in Fig. 3(a) are listed in Table 2. The concentration of Al within precipitates in $\alpha-\mathrm{Mg}$ matrix is significantly higher than the nominal content of $6 \mathrm{wt} . \% \mathrm{Al}$, which can be denoted 
as an Al-enriched phase, as marked in Fig. 1. These precipitates act as cathodes versus the surrounding $\alpha-\mathrm{Mg}$, the adjacent $\mathrm{Mg}$ may dissolve preferentially and the Al-enriched phase would detach from the surface correspondingly. The EDS results of $\alpha$-Mg for the as-cast and T5 alloys in

Table 2 show lower concentrations of $\mathrm{Al}$ and $\mathrm{Zn}$ compared with the nominal compositions, indicating that the segregation of $\mathrm{Al}$ and $\mathrm{Zn}$ occurred during the crystallization.

\subsection{Corrosion performance}

\subsubsection{Hydrogen evolution and mass loss}

Gas collection is equivalent to employing a weight-loss method for corrosion rate testing for magnesium alloys, and is more convenient for calculating the average corrosion rate over a given period [34]. In the current work, the corrosion rate is investigated by both hydrogen evolution and weight-loss tests simultaneously for each sample in 3.5 wt.\% NaCl. Fig. 4 illustrates the average hydrogen evolution rates and mass loss rates of as-cast, T4, and T5 alloys in $3.5 \mathrm{wt} . \% \mathrm{NaCl}$ over a $24 \mathrm{~h}$ period.

As shown in Fig. 4(a), the corrosion rates of all three alloys increase with immersion time. The corrosion rate of T5 alloy is higher than that of the as-cast alloy throughout the test period. This is probably due to the larger amount of precipitates of T5 alloy, which act as micro-cathodes [19, 3436] in forming the micro-cells. During the early period of immersion, the relative corrosion rates of the three alloys within the region denoted as section A in Fig. 4(a) can be ranked as T5 > as-cast > T4. However, as shown in sections B and C of Fig. 4(a), the corrosion rate of the T4 alloy gradually exceeds both the as-cast and T5 alloys with immersion time. At the end of $24 \mathrm{~h}$, the corrosion rates of the three alloys can be ranked as T4 $>$ T5 $>$ as-cast. The average mass loss rates presented in Fig. 4(b) are in good agreement with the results within section C of Fig. 4(a). These results is also 
consistent with the suggestion of Wang et al. [36], which reported that the existence of precipitates decreased the corrosion rate.

Fig. 5 presents the corrosion morphologies of AZ63 alloys with corrosion products (at left) and with corrosion products removed (at right) after immersion for $24 \mathrm{~h}$. The corrosion products of the T4 alloy shown in Fig. 5(c) are finer than those of the as-cast and T5 alloys shown in Figs. 5(a) and (e), whose morphologies show some blocking characteristics. Thus, it is possible to deduce that the corrosion products on the T4 alloy surface are not apt to form a protective outer crust, and are less adhesive than the corrosion products on the as-cast and T5 alloy surfaces. Fig. 5(b), (d), and (f) present the corroded morphologies of the as-cast, $\mathrm{T} 4$, and $\mathrm{T} 5$ alloys after removal of the corrosion products. Corrosion of the as-cast alloy tends to develop vertically from the surface, leaving bulky secondary phases distributed randomly as shown in Fig. 5(b). The T4 alloy surface exhibits a relatively uniform morphology identified by shallow and widespread holes in Fig. 5(d). A large number of miniscule pockets of secondary phases which distribute densely and homogeneously, remaining on the corroded surface of the T5 alloy are shown in Fig. 5(f). Additionally, a tendency for the vertical development of corrosion is noted at some sites on the T5 alloy surface.

Fig. 6 presents the EDS results of the remaining phase on the as-cast alloy surface after removal of the corrosion products. The laminar structure is comprised of some $\mathrm{Al}$ (Location A) or $\mathrm{Zn}$ (Location B) enriched phase, which acts as micro-cathode for corrosion, resulting in preferential dissolution of $\alpha-\mathrm{Mg}$.

\subsubsection{Open Circuit Potential}

The OCP values of the AZ63 alloys are shown in Fig. 7. As reported in [38], an increasing OCP indicates the initiation and propagation of corrosion, whereas relatively stable OCP values imply a 
steady state between the advance of corrosion and the deposit of corrosion products. For short-term immersion (Fig. 7a, $1800 \mathrm{~s}$ ), the OCP of the T4 alloy increases with the immersion time. This could be attributed to a longer incubation period (greater than $1800 \mathrm{~s}$ ) for the localized corrosion of the T4 alloy as a result of a relatively stable and protective oxide film. The OCPs of the as-cast and T5 alloys increase to peak values rapidly, and then reduce to relatively stable values during short-term immersion. This could be interpreted as the immediate deterioration of the oxide film in the $\mathrm{Cl}^{-}$ contained solution [39]. As demonstrated in [40], the incubation period of localized corrosion decreases as the peak in the OCP diagram appears increasingly early. The T5 alloy exhibits an OCP peak earlier than the as-cast alloy, indicating a shorter activated period of localized corrosion, which is probably induced by the large amount of precipitates. In addition, the OCP of the T5 alloy becomes relatively stable earlier than does the as-cast alloy, indicating an immediate establishment of steady state between localized corrosion and deposition of corrosion products.

As shown in Fig. 7(b), which presents the OCP values obtained during long-term immersion testing $(654 \mathrm{~h})$. The OCP values of all three alloys initially increase, and then maintain relatively stable values after immersion for about $200 \mathrm{~h}$. This could be attribute to the formation of an autocatalytic corrosion cell [19] due to the accumulation of corrosion products on the alloy surfaces. In addition, the fluctuation of OCP values with time is probably due to the corrosion product layer induced competition between localized corrosion and passivation [40]. The stable OCP values of the alloys considered can be ranked as T5 < as-cast $<\mathrm{T} 4$, where the T4 alloy exhibits the most positive values due to the absence of precipitates on grain boundaries (see Fig. 1b), which act as cathodes versus $\alpha-\mathrm{Mg}$ on promoting the corrosion. The average values with standard deviations of OCP for the entire periods considered in Fig. 7(a) and (b) are listed in Table 3. The observed 
variations among the three alloys during the $1800 \mathrm{~s}$ and $654 \mathrm{~h}$ periods are very tiny, implying that the influence of heat treatment on AZ63 alloy does not actually alter the driving force of corrosion.

The phase of the corrosion products revealed by the XRD patterns are shown in Fig. 8. The major phase of the corrosion products are $\mathrm{Mg}(\mathrm{OH})_{2}$ and $\mathrm{MgO}$, which is consistent with the description provided by Song and Unocic [41], i.e., the inner and outer product films are comprised of mixtures of micro-porous $\mathrm{MgO}+\mathrm{Mg}(\mathrm{OH})_{2}$. Additionally, some crystalline hydrate phase of $\mathrm{Mg}$ and $\mathrm{Al}$ are detected. $\mathrm{Zn}$, which is not detected in the corrosion products, is assumed to have been dissolved into solution during the corrosion process [20].

\subsubsection{Potentiodynamic Polarization Curves}

To further investigate the variations of corrosion rate with respect to immersion time, potentiodynamic polarization tests on the AZ63 alloys were conducted after different immersion times (10 min, $1 \mathrm{~h}, 6 \mathrm{~h}, 12 \mathrm{~h}$, and $24 \mathrm{~h})$. As the as-cast, T4 and T5 alloys exhibit similar polarization behaviors during the testing, the schematic polarization curve is presented in Fig. 9(a) for simplicity. The anodic branch does not exhibit Tafel characteristic, and is not as steep as the cathodic branch, implying that the cathodic reaction dominants the corrosion process. In contrast to the anodic branch, the cathodic branch exhibits linear Tafel characteristic at potentials more negative than the critical pitting potential $\left(\mathrm{E}_{\mathrm{pt}}\right)[42]$.

As reported in [2, 43-45], the cathodic current associated with the reduction of oxygen can be neglected due to the oxygen reduction is not considered to be important for Mg corrosion, thus the cathodic process within the Tafel region is mainly the hydrogen evolution in solution. Anodic polarization curves of magnesium and its alloys may be complicated due to the negative difference effect (NDE), which enhances hydrogen evolution when the alloy is anodized [19]. Consequently, 
the Tafel extrapolation for corrosion current calculation can be conducted by the method illustrated in Fig. 9(a). The calculated corrosion current densities with respect to immersion time of all three alloys are shown in Fig. 9(b). The current densities increase with increasing immersion time, indicating that the corrosion is promoted during the immersion. The corrosion rate of the T5 alloy is higher than that of the as-cast alloy throughout the testing, while the corrosion of the T4 alloy (which initially has the lowest corrosion rate) increases rapidly, and attains the highest corrosion rate among the three alloys considered. These results are consistent with the tendency of hydrogen evolution testing illustrated in Fig. 4(a).

Fig. 9(c) presents the polarization curves obtained after immersion for $10 \mathrm{~min}$, where the curves exhibit similar cathodic branches, implying that the microstructure has little influence on the mechanism of cathodic reaction. The free corrosion potential, representing the corrosion tendency of the alloys, can be ranked as T4 > as-cast > T5, which could be interpreted according to the increasing fraction of precipitates in the three alloys. The anodic branch of the T4 alloy is smoother than those of the as-cast and T5 alloys during anodic polarization, indicating that the T4 alloy has the highest anodic dissolution activity. The anodic branches obtained at the other immersion times considered ( $1 \mathrm{~h}, 6 \mathrm{~h}, 12 \mathrm{~h}$, and $24 \mathrm{~h}$ ) are quite similar to those obtained after immersion for $10 \mathrm{~min}$, which are probably owing to the less protective finer corrosion products on the T4 alloy surface as shown in Fig. 5(c). This is also supported by the work of Song and Unocic [41], which advocated that the finer corrosion products were less adhesive to the alloy surface with correspondingly reduced corrosion resistance.

\subsubsection{Electrochemical impedance spectroscopy (EIS)}

Nyquist diagrams of as-cast, homogenized (T4), and peak-aged (T5) alloys obtained at various 
immersion times (10 min, $1 \mathrm{~h}, 12 \mathrm{~h}$, and $24 \mathrm{~h}$ ), exhibiting various electrochemical characteristics are presented in Fig. 10. As shown in Fig. 10(a), the EIS spectra of the three alloys are comprised of two capacitive loops at high and low frequencies after immersion for 10 min. Changes in the EIS spectra with increasing immersion time are presented in Figs. 10(b), (c), and (d), which represent the dynamic characteristics of the dissolving surfaces. Here, the low-frequency capacitive loop disappears, and the spectra are comprised of a single high-frequency capacitive loop and two inductive loops at middle and low frequencies after immersion, except for the T4 alloy for $1 \mathrm{~h}$ immersion, which exhibits only a single inductive loop at low frequency (see Fig. 10(b)).

Of the initial two capacitive loops, the larger loop at high frequency is related to the electric double layer at the electrode/electrolyte interface [12], and its diameter is estimated equal to the charge transfer resistance of the working electrode. The smaller loop at low frequency is due to the relaxation of mass transport of dissolution products in the partially protective oxide layer [18, 26, 46-48]. The dissolving surface model of AZ63 alloy at the initial immersion stage is illustrated in Fig. 11(a). The electric double layer formed by electrolyte and bare AZ63 alloy surface without oxide film is located at the electrode/electrolyte interface, its electric property could be expressed by a resistance and a capacitor in parallel connection. The sum of the resistances of all pores in the oxide layer and the sum of oxide layer induced capacitances are in proximity to the AZ63 alloy matrix. The pore resistance should connect with electric double layer in series, and as a whole, connect with oxide layer induced capacitor in parallel way owing to the physical characteristic on the electrode surface.

With the increasing immersion time, the oxide layer is broken down progressively, and the corrosion products are gradually generated. In Figs. 10(b), (c), and (d), the inductive loops appear 
at middle and low frequencies, which could be attribute to the desorption of corrosion products and the reaction of $\mathrm{Mg}^{+}$with $\mathrm{H}_{2} \mathrm{O}$ at the damaged areas of the corrosion products film [49, 50]. As shown in Fig. 10(b), the EIS spectrum of the T4 alloy presents only a single inductive loop at low-frequency after $1 \mathrm{~h}$ immersion, which could be ascribed to either the absence of corrosion products or the desorption of corrosion products is too weak to be detected in the first immersion hour. This assumption is also supported by the relative low corrosion rate of the T4 alloy at initial stage, as demonstrated by the hydrogen evolution and Tafel extrapolation shown in Fig. 4(a) and Fig. 9(b). Thus, this single inductive loop should be induced by the reaction of $\mathrm{Mg}^{+}$with $\mathrm{H}_{2} \mathrm{O}$. In addition, the decreasing sizes of the loops indicated by a comparison of Figs. 10(a) to (d), particularly for that of the T4 alloy, imply that the corrosion rates of all three alloys increase substantially. Fig. 11(b) simulate the actual characteristics of the AZ 63 alloy dissolving surface over $1 \mathrm{~h}$ immersion. The electric double layer on the bare alloy surface could be described by a resistance and a capacitor in parallel connection as discussed above. The corrosion products desorption and the $\mathrm{Mg}^{+}$ions react with $\mathrm{H}_{2} \mathrm{O}$ processes could be connected with electric double layer in parallel connection due to these three electrochemical/chemical characteristics are both taken place simultaneously on the bare surface.

The equivalent circuits given in Fig. 11(c), (d) and (e) are adopted to fit the Nyquist plots shown in Fig. 10. Here, $R_{s}$ is the solution resistance, $R_{t}$ and $Q_{d l}$ are the charge transfer resistance and the capacitor of the electric double layer respectively. The constant phase element (CPE) denoted as Q is in consideration of the deviation effect for the electric double layer induced capacitor. $R_{f}$ is the resistance of the oxide layer, and the $Q_{f}$ is substituted for the capacitor of the oxide layer. A parallel connection of $Q_{f}$ and $R_{f}$ is employed for describing the low frequency characteristic in Fig. 10(a), 
and denotes the resistance and capacitive characteristic of the oxide film [18, 42]. $R_{L M g+}$ and $L_{M g+}$ in series represent the middle-frequency inductance, which describes the $\mathrm{Mg}^{+}$reaction with $\mathrm{H}_{2} \mathrm{O}$ at the damaged areas of the corrosion products film $[52,53] . R_{L}$ and $L$ in series represent the lowfrequency pseudo resistance and inductance resulting from the desorption of the corrosion products film $[1,51]$.

The polarization resistance $R_{p}$ is an important parameter due to $1 / R_{p}$ is believed to be proportional to the corrosion rate $[49,52]$. According to the equivalent circuits given in Fig. $11, R_{p}$ can be calculated as follows.

equivalent circuit (c):

$$
R_{p}=R_{f}+R_{t}
$$

equivalent circuit (d):

$$
R_{p}=\frac{R_{t} R_{L_{M g+}}}{R_{t}+R_{L_{M g+}}}
$$

equivalent circuit (e):

$$
R_{p}=\frac{R_{t} R_{L} R_{L_{M g+}}}{R_{t} R_{L}+R_{L} R_{L_{M g+}}+R_{t} R_{L_{M g+}}}
$$

The calculated values of $1 / R_{p}$ as a function of immersion time are presented in Fig. 12. The diagrams illustrate the increasing corrosion rates with immersion time. The corrosion rate of the ascast alloy is less than that of the T5 alloy throughout the testing. The T4 alloy initially exhibits a lower corrosion rate than the as-cast and T5 alloys do, but its corrosion rate exceeds those of the other two alloys after immersion for $12 \mathrm{~h}$. This tendency also agree with the results obtained from the hydrogen evolution and Tafel extrapolation results discussed above.

\subsubsection{Mott-Schottky}


The Mott-Schottky (M-S) relation, which describes the potential dependence of the space charge capacity of a semiconductor electrode surface under a depletion condition [53], can be employed to determine the electronic properties of corrosion products film in the case of anodic polarization once the corrosion products film on alloys exhibits a semiconducting characteristic [34, 54]. The charge distribution at the interface of corrosion products film and electrolyte is always determined by measuring the capacitance of the space charge layer $\left(C_{s c}\right)$ as a function of the electrode potential $(E)$. The interfacial capacitance obtained from $C=-1 /\left(\omega Z^{\prime \prime}\right)$ is equal to the space charge capacitance. The measured capacitance $\mathrm{C}$ is equal to the 'space charge' capacitance, $C_{s c}$. The space charge capacitance of an n-type semiconductor is given as follows,

$$
C^{-2}=\frac{2}{\varepsilon \varepsilon_{0} e N_{D} A^{2}}\left(V-V_{f b}-\frac{k T}{e}\right)
$$

where $A$ is the area of the film, $\varepsilon_{0}$ is the permittivity of vacuum $\left(8.854 \times 10^{-14} \mathrm{~F} / \mathrm{cm}\right), \varepsilon$ is the dielectric constant of the corrosion products $\left(\mathrm{Mg}(\mathrm{OH})_{2}\right.$ is about 3.8), $N_{D}$ is the donor concentration in the corrosion products film, which is determined by the slope of the experimental $1 / C^{2}$ versus potential (E). $V$ is the applied anodic potential, $V_{f b}$ is the flat band potential, $e$ is the charge of the electron $\left(1.602 \times 10^{-19} \mathrm{C}\right)$, and $k$ is the Boltzmann constant $\left(1.38 \times 10^{-23} \mathrm{~J} / \mathrm{K}\right)$, where $k T / e$ is about $25 \mathrm{mV}$ at ambient temperature.

As-cast, T4, and $\mathrm{T} 5$ alloys have been immersed in $3.5 \mathrm{wt} . \% \mathrm{NaCl}$ for $24 \mathrm{~h}$ aiming at forming a continuous products film prior to conducting M-S testing. For the n-type semiconductor, $C^{-2}$ versus $V$ should be linear with a positive slope. The imaginary part of the impedance for as-cast and T5 alloys as a function of potential are presented in Fig. 13 at a frequency of $1 \mathrm{kHz}$ for the as-cast and T5 alloys, assuming that the capacitance of the Helmholtz double layer could be neglected [34]. T4 alloy, which is not illustrated in Fig.13, exhibits a non-linear relationship, implying non- 
semiconductor characteristic of the corrosion products probably due to the poor adhesive capability. The profiles of the as-cast and T5 alloys exhibiting positive linear slopes over the entire scanning potential range are characterized as n-type semiconductors, where the donor levels in the products film increase with increasing anodic polarization potentials. The lower slope of the T5 alloy shown in Fig. 13 implies a higher donor concentration in the film than that of the as-cast alloy. This could be interpreted according to the following electrochemical and chemical reaction equations [42, 44].

$$
\begin{aligned}
\mathrm{Mg} & \rightarrow \mathrm{Mg}^{+}+\mathrm{e}^{-} \\
\mathrm{Mg}^{+} & \rightarrow \mathrm{Mg}^{2+}+\mathrm{e}^{-} \\
\mathrm{Mg}^{+}+\mathrm{H}_{2} \mathrm{O} & \rightarrow \mathrm{Mg}^{2+}+\mathrm{OH}^{-}+\frac{1}{2} \mathrm{H}_{2}
\end{aligned}
$$

Equation (5) describes the first step of anodic dissolution process, which supplies $\mathrm{Mg}^{+}$to the surface film via electrochemical reaction. $\mathrm{Mg}^{+}$is subsequently oxidized to $\mathrm{Mg}^{2+}$ via the chemical and electrochemical reaction given in Equation (6) and (7), which occurs at the damaged areas of the surface film [42]. The concentration of $\mathrm{Mg}^{+}$determines the corrosion rate, and acts as a donor in the products film due to the reaction described by Equation (5) is the determining step of the anodic dissolution reaction. The volume fraction of the cathodic phase of the T5 alloy is higher than that of the as-cast alloy by comparing with Figs. 1(a) and (c), implying a more convenient formation of micro-galvanic couples on the T5 alloy surface, and, as a consequence, the T5 alloy could provide more $\mathrm{Mg}^{+}$, which act as donor via anodic dissolution than that of the as-cast alloy. This interpretation may explain the lower corrosion rate of the as-cast alloy as compared with that of the T5 alloy.

\subsection{Corrosion mechanism}

\subsubsection{Influence of precipitates on corrosion rate}

Since the corrosion rate of magnesium and its alloys can be evaluated by hydrogen evolution at 
the free corrosion potential, the value of the cathodic current could be employed to characterize the corrosion rate. A partially protective film mechanism is adopted in the current work due to the products film on an Mg electrode surface has a porous microstructure [42], assuming an area fraction $\theta$, where $0<\theta<1$, which describes the area ratio of alloy surface without corrosion products film. Based on this assumption, the hydrogen evolution current can be expressed as [2]

$$
I_{c}=\theta I_{c 0} \exp \left[\frac{-\left(E-E_{c e}\right)}{b_{c 0}}\right]+(1-\theta) I_{c p} \exp \left[\frac{-\left(E-E_{c e}\right)}{b_{c p}}\right]
$$

where $I_{c 0}, b_{c o}$, and $E_{c e}$ are the exchange current density, Tafel slope, and equilibrium potential of the cathodic process on a bare sample surface, respectively. $I_{c p}$ and $b_{c p}$ are the exchange current density and Tafel slope on a sustained and protective products film, and $E$ is the electrode potential.

It is believed that both the anodic and cathodic reactions occur with greater difficulty on a filmcovered area than on the bare metal surface [42]. As such, $b_{c p}$ approaches infinity and $I_{c p}$ approaches zero. In this case, Equation (8) can be simplified as follows.

$$
I_{c}=\theta I_{c 0} \exp \left[\frac{-\left(E-E_{c e}\right)}{b_{c 0}}\right]
$$

Based on the suggestion proposed by Song et al. [2], $\theta$ is a function of $E$. In the present study, another parameter $\xi$ is employed as an independent variable of $\theta$ to define the area ratio of the microcathodes to the micro-anodes exposed to solution, which represents the corrosion tendency of an electrode, where the corrosion would be enhanced with increasing $\xi$. The derivative of $I_{c}$ with respect to time could then be expressed as follows.

$$
\frac{\mathrm{d} I_{c}(\xi)}{\mathrm{d} t}=I_{c 0} \exp \left[\frac{-\left(E-E_{c e}\right)}{b_{c 0}}\right]\left\{\frac{\mathrm{d}[\theta(\xi)]}{\mathrm{d} \xi} \frac{\mathrm{d} \xi}{\mathrm{d} t}-\frac{\theta}{b_{c 0}} \frac{\mathrm{d} E}{\mathrm{~d} t}\right\}
$$

To simplify the model, $E$ is regarded as a constant due to the corrosion occurs at the free corrosion potential, and, as such, $\mathrm{d} E / \mathrm{d} t \approx 0$. Therefore, Equation (10) can be simplified as follows. 


$$
\frac{\mathrm{d} I_{c}(\xi)}{\mathrm{d} t}=I_{c 0} \exp \left[\frac{-\left(E-E_{c e}\right)}{b_{c 0}}\right] \frac{\mathrm{d}[\theta(\xi)]}{\mathrm{d} \xi} \frac{\mathrm{d} \xi}{\mathrm{d} t}
$$

Due to the corrosion initiates nearby the micro-cathodic phase, the micro-galvanic reaction would be enhanced as the increasing volume of the micro-cathodic phase (i.e. $\zeta$ ), which promotes the stirring effect due to the enhanced hydrogen evolution. As a result, the adhesiveness of the corrosion products would decrease, and the following expression could be obtained.

$$
\frac{\mathrm{d}[\theta(\xi)]_{E_{0}}}{\mathrm{~d} \xi}>0
$$

Continuous dissolution of $\alpha-\mathrm{Mg}$ exposes an increasing area of the cathodic phase with time through the corrosion process, thus,

$$
\frac{\mathrm{d} \xi}{\mathrm{d} t}>0
$$

Combining Equations (11), (12), and (13) yields,

$$
\frac{\mathrm{d} I_{c}(\xi)}{\mathrm{d} t}>0
$$

Equation (14) explains the observed increases for the corrosion rates of the as-cast and T5 alloys discussed above.

The stirring effect caused by hydrogen evolution for the T5 alloy would be more intense than that for the as-cast alloy due to the relatively large volume fraction of cathodic phase. In addition, hydrogen bubbles appear mainly on the crevices of the developing products film during the corrosion. As shown in Fig. 5(e), the crevices of the T5 alloy are wider and deeper than those shown in Fig. 5(a) for the as-cast alloy, which further suggests a more intense stirring effect owing to hydrogen evolution for the T5 alloy. Thus, the relative values of $\theta$ might agree with the following relationship.

$$
\theta_{E_{0}, \mathrm{~T} 5}>\theta_{E_{0}, \text { as-cast }}
$$


As shown in potentiodynamic polarization section, the cathodic reactions of the investigated alloys exhibit similar behaviors, thus, the slopes of cathodic Tafel branches of the as-cast and T5 alloys are estimated to be equal to each other (see Fig. 9(c)). Consequently,

$$
\left|b_{c 0, \mathrm{~T} 5}\right| \approx\left|b_{c 0, \text { as-cast }}\right|
$$

$E_{\mathrm{T} 5}$ is more negative than $E_{\text {as-cast }}$ according to comparing with the free corrosion potentials shown in Fig. 9(c), then,

$$
\exp \left[\frac{-\left(E_{\mathrm{T} 5}-E_{c e, \mathrm{~T} 5}\right)}{b_{c 0, \mathrm{~T} 5}}\right]>\exp \left[\frac{-\left(E_{\text {as-cast }}-E_{c e, \text { as-cast }}\right)}{b_{c 0, \text { as-cast }}}\right]
$$

In Equation (17), the miniscule difference between $E_{c e}$, T5 and $E_{c e}$, as-cast have been neglected. The value of $I_{c 0}$ for the T5 alloy might be greater than that of the as-cast alloy due to its large volume fraction of precipitates on grain boundaries. The following relationship could be yielded via bringing Equations (15), (17) into (9).

$$
I_{c, \mathrm{~T} 5}>I_{c, \text { as-cast }}
$$

Equation (18) interprets the experimentally established relationship of corrosion rates ranked as T5 > as-cast.

However, Equations (14) and (18) should accord with the following assumptions. (1) Sufficient areas of $\alpha-\mathrm{Mg}$ for anodic dissolution are exposed to solution with increasing immersion time. The corrosion rate would not increase with insufficient anodic area, which is responsible to supply electrons even though with increasing $\xi$. Consequently, the corrosion rate would attain a relatively stable value once an equilibrium between the dissolution of $\alpha-\mathrm{Mg}$ and the desorption of cathodic phase has been established, rather than increase infinitely with increasing immersion time. (2) The structure of cathodic phase remaining on the surface should be not compact (see Fig. 5(b)). It is believed that the over intensive second phase would limit the corrosion due to the shielding effect 
on electrons transfer [19]. (3) The dissolution rates of the $\alpha-\mathrm{Mg}$ of the as-cast and T5 alloys are estimated equal to each other even though it has been reported that the dissolution rates of $\alpha-\mathrm{Mg}$ definitely decrease with increasing $\mathrm{Al}$ concentration $[52,53]$. In this work, the difference on corrosion rate between as-cast and T5 alloys could be ignored due to the EDS results given in Table 2, which imply that the concentration difference of $\mathrm{Al}$ and $\mathrm{Zn}$ for the as-cast and $\mathrm{T} 5$ alloys are small.

\subsubsection{Corrosion behavior of the AZ63 alloy}

As reported in [20], the protective film on the $\alpha-\mathrm{Mg}$ of AZ series magnesium alloys consists of three layers: an inner layer riches in $\mathrm{Al}_{2} \mathrm{O}_{3}$, a middle layer riches in $\mathrm{MgO}$, and an outer layer of $\mathrm{Mg}(\mathrm{OH})_{2}$; yet, a protective film of only two layers comprises of an inner $(\mathrm{Mg}, \mathrm{Al})_{\mathrm{x}} \mathrm{O}_{\mathrm{y}}$ layer and an outer $(\mathrm{Mg}, \mathrm{Al})_{x}(\mathrm{OH})_{\mathrm{y}}$ layer is observed on the $\beta-\mathrm{Mg}_{17} \mathrm{Al}_{12}$ phase. The passive film on the $\beta$-phase is very stable over a given range of $\mathrm{pH}$ values $[20,45]$. Therefore, the oxide layer could be distinguished as active section and stable section as shown in Fig.14 considering that the influence of micro-pores on oxide film has been neglected.

Fig. 14 presents the dynamic corrosion process of as-cast and T5 treated alloys. The corrosion initiates easily on as-cast and T5 alloys due to the formation of micro-galvanic couples between the different protective films on the $\alpha-\mathrm{Mg}$ and $\beta-\mathrm{Mg}_{17} \mathrm{Al}_{12}$ phases. As the corrosion processing, the active oxide layer is consumed continuously rather than falling off as stable layer. Consequently, the corrosion products is generated and accumulate in the localized corroded area. The corrosion develops along the grain boundary, which is consisted of eutectic $\alpha$ phase and $\beta-\mathrm{Mg}_{17} \mathrm{Al}_{12}$ phase, the eutectic $\alpha$ phase adjacent to $\beta-\mathrm{Mg}_{17} \mathrm{Al}_{12}$ phase is corroded preferentially owing to their high potential difference [19], and then the corrosion spreads to the $\alpha$-Mg gradually. In this case, the area ratio of cathodic area to anodic area $(\xi)$ exposed to electrolyte would increase subsequently 
regardless of porous corrosion products accumulation. Thus, the increasing corrosion rates of ascast and T5 alloys detected in the hydrogen evolution and electrochemical experiments are interpreted by this model. Meanwhile, this model can also explain the stable corrosion rate obtained after a certain period immersion. The stable corrosion rate with slight fluctuation is owing to the established dynamic equilibrium between the increasing area ratio of cathodic area to anodic area $(\xi)$ and falling off of discontinuous $\beta-\mathrm{Mg}_{17} \mathrm{Al}_{12}$ phase as shown in Fig. 14.

The T4 alloy initially exhibits the lowest corrosion rate (see Fig. 4(a), Fig. 9(b), and Fig. 10) and then increases rapidly to the highest value among the three alloys investigated. This finding is not consistent with some studies $[17,57,58]$, which proposed that homogenization decreases the corrosion rate via dissolution of precipitates on grain boundaries. However, it should be noted that these studies did not evaluate the corrosion rate over extending immersion periods. It is believed that the oxide film on homogenized AZ 63 alloys is estimated sustained and protective [26], therefore, the investigation for $\mathrm{T} 4$ treated alloy must consider the influence of oxide film and the work ignoring the evolution of surface state are unilateral and unconvincing. The present work establishes an absence of precipitates on the grain boundaries of the $\mathrm{T} 4$ alloy, revealing a different corrosion mechanism from those of the as-cast and T5 alloys.

Fig. 15 presents the corrosion schematic of homogenized (T4) alloy in the early period of immersion. As mentioned above, the oxide film constituent on T4 alloys should be very close to on the $\alpha-\mathrm{Mg}$ grains with three layers structure, this relatively uniform and stable protective film of the T4 alloy [59] tends to dissolve more slowly by comparing the protective films to those of the ascast and T5 alloys at beginning owing to the absence of micro-galvanic couples.

The film on T4 alloy has defects owing to the Pilling-Bedworth ratio of $\mathrm{Mg}$ is about 0.81 , the 
exposed alloy matrix via the 'honeycomb pores' marked in Fig. 15 would dissolve preferentially, and some corrosion products are generated subsequently. As a consequence, the interior of the defects are subjected to alkalization with time ascribing to the accumulation of $\mathrm{Mg}(\mathrm{OH})_{2}$, whose equilibrium $\mathrm{pH}$ of saturated solution is about 11 [60]. The alkalization makes the dissolution rate of matrix covered with $\mathrm{Mg}(\mathrm{OH})_{2}$ decrease, and other areas with weak protective film would become new micro-anodes. The dissolution of the oxide film develops in a widespread way until the film is dissolved completely. After that, the corrosion process may be quite similar to that of $\alpha-\mathrm{Mg}$ grains described in [20], which exhibits the characteristic of uniform corrosion, as presented in Fig. 5(d). The results revealed by the tests are also supported by the works announcing that the existence of $\beta$ phase, which is rich in aluminum, may depress the corrosion attack of the alloy [22, 32].

\section{Conclusions}

In summary, the corrosion behaviors of as-cast, homogenized (T4), and peak-aged (T5) AZ63 alloys are investigated in this work. The corrosion rates of AZ63 alloys are determined by a combined effects of precipitates fraction and the film properties. Two corrosion mechanisms for interpreting the corrosion behaviors of the alloys are proposed in this work and the tentative conclusions are given as follows.

1. In the beginning of immersion, the protective oxide layer on homogenized alloy retarded the corrosion. However, the micro-galvanic couples form by differential activity oxide layers on as-cast and peak-aged alloys endow the alloys a higher activity.

2. Following by the depletion of oxide film, the corrosion of as-cast and peak-aged alloys are dominated by micro-galvanic mechanism due to the existence of $\beta-\mathrm{Mg}_{17} \mathrm{Al}_{12}$ phase. The homogenized alloy with highest corrosion rate is attributed to the less adhesive corrosion products 
of homogenized alloy providing poor protective property comparing with those on as-cast and peakaged alloys. Besides the high aluminum concentration in $\alpha-\mathrm{Mg}$ grains is another impact factor.

3. A new independent variable $\xi$, defined as the ratio of the micro-cathode area to the micro-anode area as a function of the area fraction $\theta$ without corrosion product film, is proposed to characterize the corrosion trends. The increasing precipitates on grain boundaries, which promotes the corrosion, is interpreted qualitatively by substituting $\theta(\xi)$ into the partially protective model.

\section{Acknowledgement}

The authors wish to acknowledge the financial support of the National Science Foundation of China (No.41476067; No.41276074; No.51501180; No.51501181). The authors are also grateful to Dr. Weichen Xu and Dr. Meng Zheng for the revision of language.

\section{References}

[1] G.-L. Song, Z. Shi, Corrosion mechanism and evaluation of anodized magnesium alloys, Corros. Sci. 85 (2014) 126-140.

[2] G.L. Song, A. Atrens, D. Stjohn, J. Nairn, Y. Li, The electrochemical corrosion of pure magnesium in $1 \mathrm{~N} \mathrm{NaCl,}$ Corros. Sci. 39 (1997) 855-875.

[3] A. Pardo, M.C. Merino, R. Arrabal, P. Casajus, M. Mohedano, S. Feliu, Jr., S. Merino, Corrosion behavior of AZ magnesium alloys with $\mathrm{Al}$ and $\mathrm{Al}-11 \mathrm{Si}$ thermal spray coatings, Corrosion. 67 (2011).

[4] Z. Grubač, I.Š. Rončević, M. Metikoš-Huković, Corrosion properties of the Mg alloy coated with polypyrrole films, Corros. Sci. 102 (2016) 310-316.

[5] X. Li, Z. Weng, W. Yuan, X. Luo, H.M. Wong, X. Liu, S. Wu, K.W.K. Yeung, Y. Zheng, P.K. Chu, Corrosion resistance of dicalcium phosphate dihydrate/poly(lactic-co-glycolic acid) hybrid coating on AZ31 magnesium alloy, Corros. Sci. 102 (2016) 209-221.

[6] A.S. Gnedenkov, S.L. Sinebryukhov, D.V. Mashtalyar, S.V. Gnedenkov, Protective properties of inhibitorcontaining composite coatings on a Mg alloy, Corros. Sci. 102 (2016) 348-354.

[7] H.Y. Ha, J.Y. Kang, J. Yang, C.D. Yim, B.S. You, Role of Sn in corrosion and passive behavior of extruded Mg5 wt.\%Sn alloy, Corros. Sci. 102 (2016) 355-362.

[8] A.S. Gnedenkov, S.L. Sinebryukhov, D.V. Mashtalyar, S.V. Gnedenkov, Localized corrosion of the Mg alloys with inhibitor-containing coatings: SVET and SIET studies, Corros. Sci. 102 (2016) 269-278.

[9] M. Shinohara, E. Araki, M. Mochizuki, T. Kanazawa, K. Suyehiro, Practical application of a sea-water battery 
in deep-sea basin and its performance, J. Power. Sources. 187 (2009) 253-260.

[10] O. Hasvold, T. Lian, E. Haakaas, N. Storkersen, O. Perelman, S. Cordier, CLIPPER: a long-range, autonomous underwater vehicle using magnesium fuel and oxygen from the sea, J. Power. Sources.136 (2004) 232-239.

[11] S. Johnston, Z. Shi, A. Atrens, The influence of $\mathrm{pH}$ on the corrosion rate of high-purity Mg, AZ91 and ZE41 in bicarbonate buffered Hanks' solution, Corros. Sci. 101 (2015) 182-192.

[12] R. Udhayan, D.P. Bhatt, On the corrosion behaviour of magnesium and its alloys using electrochemical techniques, J. Power. Sources. 63 (1996) 103-107.

[13] H.X. Jin, R.C. Wang, C.Q. Peng, K. Shi, Y. Feng, Effect of indium addition on corrosion of AP65 magnesium alloy, J. Cent. South. Univ. 19 (2012) 2086-2093.

[14] K. Gusieva, C.H.J. Davies, J.R. Scully, N. Birbilis, Corrosion of magnesium alloys: the role of alloying, Int. Mater. Rev. 60 (2015) 169-194.

[15] K. Yu, X. Tan, Y. Hu, F. Chen, S. Li, Microstructure effects on the electrochemical corrosion properties of Mg $-4.1 \% \mathrm{Ga}-2.2 \% \mathrm{Hg}$ alloy as the anode for seawater-activated batteries, Corros. Sci. 53 (2011) 2035-2040.

[16] J. Zhao, K. Yu, Y. Hu, S. Li, X. Tan, F. Chen, Z. Yu, Discharge behavior of Mg-4 wt.\%Ga-2 wt.\%Hg alloy as anode for seawater activated battery, Electrochim. Acta. 56 (2011) 8224-8231.

[17] N.N. Aung, W. Zhou, Effect of heat treatment on corrosion and electrochemical behaviour of AZ91D magnesium alloy, J. Appl. Electrochem. 32 (2002) 1397-1401.

[18] G. Baril, C. Blanc, N. Pebere, AC impedance spectroscopy in characterizing time-dependent corrosion of AZ91 and AM50 magnesium alloys - Characterization with respect to their microstructures, J. Electrochem. Soc. 148 (2001) B489-B496.

[19] G.L. Song, A. Atrens, M. Dargusch, Influence of microstructure on the corrosion of diecast AZ91D, Corros. Sci. 41 (1999) 249-273.

[20] G.L. Song, A. Atrens, X.L. Wu, B. Zhang, Corrosion behaviour of AZ21, AZ501 and AZ91 in sodium chloride, Corros. Sci. 40 (1998) 1769-1791.

[21] R. Arrabal, B. Mingo, A. Pardo, E. Matykina, M. Mohedano, M.C. Merino, A. Rivas, A. Maroto, Role of alloyed $\mathrm{Nd}$ in the microstructure and atmospheric corrosion of as-cast magnesium alloy AZ91, Corros. Sci. 97 (2015) 38-48.

[22] G.L. Song, A.L. Bowles, D.H. StJohn, Corrosion resistance of aged die cast magnesium alloy AZ91D, Mat. Sci. Eng. A-Struct. 366 (2004) 74-86.

[23] T. Zhang, Y. Li, F.H. Wang, Roles of beta phase in the corrosion process of AZ91D magnesium alloy, Corros. Sci. 48 (2006) 1249-1264.

[24] M. Anik, G. Celikten, Analysis of the electrochemical reaction behavior of alloy AZ91 by EIS technique in H3PO4/KOH buffered K2SO4 solutions, Corros. Sci. 49 (2007) 1878-1894.

[25] P. W. Chu, E.A. Marquis, Linking the microstructure of a heat-treated WE43 Mg alloy with its corrosion behavior, Corros. Sci. 101 (2015) 94-104.

[26] M. Anik, I.M. Guneşdoğdu, Corrosion characteristics of alloy AZ63 in buffered neutral solutions, Mater. Design. 31 (2010) 3100-3105.

[27] H. Altun, S. Sen, Studies on the influence of chloride ion concentration and $\mathrm{pH}$ on the corrosion and electrochemical behaviour of AZ63 magnesium alloy, Mater. Desin. 25 (2004) 637-643.

[28] D. Zhang, X. Zhang, X. Ge, D. Fang, X. Yu, Effect of low content Ca on the microstructures and mechanical properties of AZ63 alloys, in: W.Z. Chen, X.P. Xu, P.Q. Dai, Y.L. Chen (Eds.) Int. J. Adv.Manuf. Tech. 14, (2012) 579-582.

[29] B.G. Qian, H.R. Geng, Z.D. Tao, P. Zhao, X.F. Tian, Effects of Ca addition on microstructure and properties of AZ63 magnesium alloy, T. Nonferr. Metal. Soc. 14 (2004) 987-991.

[30] T.J. Chen, L.K. Huang, X.F. Huang, Y. Ma, Y. Hao, Effects of mould temperature and grain refiner amount on 
microstructure and tensile properties of thixoforged AZ63 magnesium alloy, J. Alloy. Compd. 556 (2013) 167-177. [31] T.J. Chen, L.K. Huang, X.F. Huang, Y. Ma, Y. Hao, Effects of reheating temperature and time on microstructure and tensile properties of thixoforged AZ63 magnesium alloy, Mater. Sci. Tech-Lond. 30 (2014) 96-108.

[32] C. Liu, Y. Xin, G. Tang, P.K. Chu, Influence of heat treatment on degradation behavior of bio-degradable diecast AZ63 magnesium alloy in simulated body fluid, Mat. Sci. Eng. A-Struct. 456 (2007) 350-357.

[33] H. Jafari, P. Amiryavari, The effects of zirconium and beryllium on microstructure evolution, mechanical properties and corrosion behaviour of as-cast AZ63 alloy, Mat. Sci. Eng. A-Struct. 654 (2016) 161-168.

[34] Y. Li, T. Zhang, F. Wang, Effect of microcrystallization on corrosion resistance of AZ91D alloy, Electrochim. Acta.51 (2006) 2845-2850.

[35] N.G. Wang, R.C. Wang, C.Q. Peng, Y. Feng, Corrosion Behavior of Magnesium Alloy AP65 in 3.5\% Sodium Chloride Solution, J. Mater. Eng. Perform. 21 (2012) 1300-1308.

[36] W. Zhou, T. Shen, N.N. Aung, Effect of heat treatment on corrosion behaviour of magnesium alloy AZ91D in simulated body fluid, Corros. Sci. 52 (2010) 1035-1041.

[37] N. Wang, R. Wang, C. Peng, Y. Feng, K. Shi, H. Jin, Effect of solid solution treatment on discharge activity of AP65 magnesium alloy anode, J. Cent. South. Univ. T. 43 (2012) 2120-2127.

[38] M.C. Zhao, M. Liu, G.-L. Song, A. Atrens, Influence of $\mathrm{pH}$ and chloride ion concentration on the corrosion of Mg alloy ZE41, Corros. Sci. 50 (2008) 3168-3178.

[39] L. Wang, B.P. Zhang, T. Shinohara, Corrosion behavior of AZ91 magnesium alloy in dilute NaCl solutions, Mater. Design. 31 (2010) 857-863.

[40] W. Liu, F. Cao, A. Chen, L. Chang, J. Zhang, C. Cao, Effect of Chloride Ion Concentration on Electrochemical Behavior and Corrosion Product of AM60 Magnesium Alloy in Aqueous Solutions, Corrosion. 68 (2012).

[41] G.L. Song, K.A. Unocic, The anodic surface film and hydrogen evolution on Mg, Corros. Sci. 98 (2015) 758765 .

[42] G.L. Song, A. Atrens, D.S. John, X. Wu, J. Nairn, The anodic dissolution of magnesium in chloride and sulphate solutions, Corros. Sci. 39 (1997) 1981-2004.

[43] G.L. Makar, J. Kruger, Corrosion of Magnesium,Int. Mater. Rev. 38 (1993) 138-153.

[44] G.R. Hoey, M. Cohen, Corrosion of Anodically and Cathodically Polarized Magnesium in Aqueous Media, J. Electrochim. Soc. 105 (1958) 245-250.

[45] G.L. Song, A. Atrens, Corrosion mechanisms of magnesium alloys, Adv. Eng. Mater. (1999) 11-33.

[46] G.L. Song, A. Atrens, X. Wu, B. Zhang, Corrosion behaviour of AZ21, AZ501 and AZ91 in sodium chloride, Corros. Sci. 40 (1998) 1769-1791.

[47] G. Baril, N. Pébère, The corrosion of pure magnesium in aerated and deaerated sodium sulphate solutions, Corros. Sci. 43 (2001) 471-484.

[48] F. Zucchi, V. Grassi, A. Frignani, C. Monticelli, G. Trabanelli, Electrochemical behaviour of a magnesium alloy containing rare earth elements, J. Appl. Electrochem. 36 (2006) 195-204.

[49] T. Zhang, G. Meng, Y. Shao, Z. Cui, F. Wang, Corrosion of hot extrusion AZ91 magnesium alloy. Part II: Effect of rare earth element neodymium (Nd) on the corrosion behavior of extruded alloy, Corros. Sci. 53 (2011) 29342942.

[50] J. Chen, J. Wang, E. Han, J. Dong, W. Ke, AC impedance spectroscopy study of the corrosion behavior of an AZ91 magnesium alloy in 0.1 M sodium sulfate solution, Electrochim. Acta. 52 (2007) 3299-3309.

[51] X. Liu, T. Zhang, Y. Shao, G. Meng, F. Wang, Effect of alternating voltage treatment on the corrosion resistance of pure magnesium, Corros. Sci. 51 (2009) 1772-1779.

[52] T. Zhang, Y. Shao, G. Meng, Z. Cui, F. Wang, Corrosion of hot extrusion AZ91 magnesium alloy: I-relation between the microstructure and corrosion behavior, Corros. Sci. 53 (2011) 1960-1968. 
[53] E. Sikora, D.D. Macdonald, Nature of the passive film on nickel, Electrochim. Acta. 48 (2002) 69-77.

[54] T. Zhang, Y. Li, F. Wang, Roles of $\beta$ phase in the corrosion process of AZ91D magnesium alloy, Corros. Sci. 48 (2006) 1249-1264.

[55] N.G. Wang, R.C. Wang, C.Q. Peng, Y. Feng, Influence of zinc on electrochemical discharge activity of Mg6\% Al-5\% Pb anode, J. Cent. South. Univ. 19 (2012) 9-16.

[56] N.G. Wang, R.-C. Wang, C.-Q. Peng, F. Yan, X.-Y. Zhang, Influence of aluminium and lead on activation of magnesium as anode, T. Nonferr. Metal. Soc. 20 (2010) 1403-1411.

[57] X.B. Liu, D.Y. Shan, Y.W. Song, E.H. Han, Effects of heat treatment on corrosion behavior of Mg-3Zn magnesium alloy, T. Nonferr. Metal. Soc. 20 (2010) 1345-1350.

[58] S.D. Wang, D.K. Xu, X.B. Chen, E.H. Han, C. Dong, Effect of heat treatment on the corrosion resistance and mechanical properties of an as-forged Mg-Zn-Y-Zr alloy, Corros. Sci. 92 (2015) 228-236.

[59] L.M. Peng, J.W. Chang, X. W. Guo, A. Atrens, W.-J. Ding, Y.-H. Peng, Influence of heat treatment and microstructure on the corrosion of magnesium alloy Mg-10Gd-3Y-0.4Zr, J. Appl. Electrochem. 39 (2009) 913-920. [60] G. Makar, J. Kruger, Corrosion studies of rapidly solidified magnesium alloys, J. Electrochem. Soc. 137 (1990) 414-421. 
Table 1 Thermal processes of the investigated AZ63 magnesium alloys

\begin{tabular}{ccc}
\hline Heat treatment & Homogenized & Peak-aged \\
\hline As cast & - & - \\
T4 & $385^{\circ} \mathrm{C}, 20 \mathrm{~h}+$ water quenching & - \\
T5 & - & $260{ }^{\circ} \mathrm{C}, 4 \mathrm{~h}+$ water quenching \\
\hline
\end{tabular}

Table 2 The EDS results of the $\alpha-\mathrm{Mg}$, grain boundaries, and precipitates like those regions marked in

Fig. 3(a) of as-cast, T4, and T5 alloys.

\begin{tabular}{ccccc}
\hline \multirow{2}{*}{ Characterization } & Alloys & $\mathrm{Mg}(\mathrm{wt} . \%)$ & $\mathrm{Al}(\mathrm{wt} . \%)$ & $\mathrm{Zn}(\mathrm{wt} . \%)$ \\
\hline \multirow{2}{*}{$\alpha-\mathrm{Mg}$} & as-cast & 95.12 & 3.17 & 1.71 \\
& $\mathrm{~T} 4$ & 91.02 & 5.94 & 3.04 \\
& $\mathrm{~T} 5$ & 95.55 & 2.63 & 1.82 \\
Grain boundary & as-cast & 89.77 & 6.42 & 3.81 \\
& $\mathrm{~T} 4$ & -- & -- & -- \\
Precipitates in $\alpha-\mathrm{Mg}$ & $\mathrm{T} 5$ & 82.3 & 11.01 & 6.69 \\
& as-cast & 45.12 & 54.58 & 0.30 \\
& T4 & 10.47 & 88.58 & 0.95 \\
\hline
\end{tabular}

Table 3 Average values of OCP (vs. SCE) of as-cast, homogenized (T4), and peak-aged (T5) alloys.

\begin{tabular}{lll}
\hline Alloys & Average OCP of $1800 \mathrm{~s}(\mathrm{~V})$ & Average OCP of $654 \mathrm{~h}(\mathrm{~V})$ \\
\hline As-Cast & $-1.570 \pm 0.005$ & $-1.522 \pm 0.013$ \\
T4 & $-1.581 \pm 0.009$ & $-1.516 \pm 0.016$ \\
T5 & $-1.579 \pm 0.003$ & $-1.533 \pm 0.010$ \\
\hline
\end{tabular}


Fig.1. SEM images of the AZ63 alloys: as-cast alloy (a); homogenized (T4) alloy (b); peak-aged (T5) alloy (c); and (d) the details of the microstructure shown in (c).

Fig. 2. XRD patterns of the AZ63 alloys: as-cast alloy (a); homogenized (T4) alloy (b); and peak-aged (T5) alloy (c).

Fig. 3. The SEM image of the as-cast alloy (a) and corresponding elemental distributions of magnesium (b), aluminum (c), and zinc (d).

Fig. 4 Hydrogen evolution rates as a function of immersion time (a), and the average mass loss rate (b) of as-cast, homogenized (T4), and peak-aged (T5) alloys in $3.5 \mathrm{wt} . \% \mathrm{NaCl}$ at $25 \pm 1{ }^{\circ} \mathrm{C}$.

Fig. 5. Corrosion morphologies of AZ63 alloys after hydrogen evolution testing for $24 \mathrm{~h}$ in $3.5 \mathrm{wt} . \% \mathrm{NaCl}$ at $25 \pm$ $1^{\circ} \mathrm{C}$ : as-cast alloy with (a) and without (b) corrosion products; homogenized (T4) alloy with (c) and without (d) corrosion products; peak-aged (T5) alloy with (e) and without (f) corrosion products.

Fig. 6. SEM image and corresponding EDS results of the corroded surface (corrosion products removed) of the as-cast alloy after hydrogen evolution testing for $24 \mathrm{~h}$ in $3.5 \mathrm{wt} . \% \mathrm{NaCl}$ at $25 \pm 1{ }^{\circ} \mathrm{C}$.

Fig. 7. Variations of the open circuit potential of as-cast, homogenized (T4), and peak-aged (T5) alloys during immersion in $3.5 \mathrm{wt} . \% \mathrm{NaCl}$ at $25 \pm 1{ }^{\circ} \mathrm{C}$ for $1800 \mathrm{~s}(\mathrm{a})$ and $654 \mathrm{~h} \mathrm{(b)}$.

Fig. 8. X-ray diffraction (XRD) patterns of the corrosion products of AZ63 alloys after immersion in 3.5 wt.\% $\mathrm{NaCl}$ at $25 \pm 1^{\circ} \mathrm{C}$ for $654 \mathrm{~h}$ : as-cast alloy (a); homogenized (T4) alloy (b) and peak-aged (T5) alloy (c).

Fig. 9. A schematic polarization curve of an AZ63 alloy (a), the corrosion current density (Icorr) as a function of immersion time (b), and polarization curves of as-cast, homogenized (T4), and peak-aged (T5) alloys after immersion in $3.5 \mathrm{wt} . \% \mathrm{NaCl}$ for $10 \mathrm{~min}$ at $25 \pm 1{ }^{\circ} \mathrm{C}$.

Fig. 10. Nyquist diagrams of as-cast, homogenized (T4), and peak-aged (T5) alloys after immersion for 10 min (a), $1 \mathrm{~h}(\mathrm{~b}), 12 \mathrm{~h}(\mathrm{c})$, and $24 \mathrm{~h}(\mathrm{~d})$ in $3.5 \mathrm{wt} . \% \mathrm{NaCl}$ at $25 \pm 1{ }^{\circ} \mathrm{C}$. 
Fig. 11. The dissolving surface model in describing the physical/chemical characteristics on the surface of alloys (a), (b) and equivalent circuits for fitting the Nyquist diagrams given in Fig.10 after immersion for 10 min (c), the homogenized (T4) alloy immersion for $1 \mathrm{~h}(\mathrm{~d})$, and all other conditions (e).

Fig. 12. The corrosion rate, as represented by the inverse polarization resistance $\left(1 / R_{\mathrm{p}}\right)$ with respect to the immersion time of as-cast, homogenized (T4), and peak-aged (T5) alloys in $3.5 \mathrm{wt} . \% \mathrm{NaCl}$ at $25 \pm 1{ }^{\circ} \mathrm{C}$.

Fig. 13. Mott-Schottky plots for the corrosion products of as-cast and peak-aged (T5) alloys after immersion in 3.5 wt. $\% \mathrm{NaCl}$ at $25 \pm 1{ }^{\circ} \mathrm{C}$ over $24 \mathrm{~h}$.

Fig. 14. Schematic of the corrosion mechanism for the as-cast and peak-aged (T5) alloys immersed in 3.5 wt.\% $\mathrm{NaCl}$ solution.

Fig. 15. Schematic of the corrosion mechanism for the homogenized (T4) alloy in the early period of immersion in 3.5 wt. $\% \mathrm{NaCl}$ solution. 
(a)
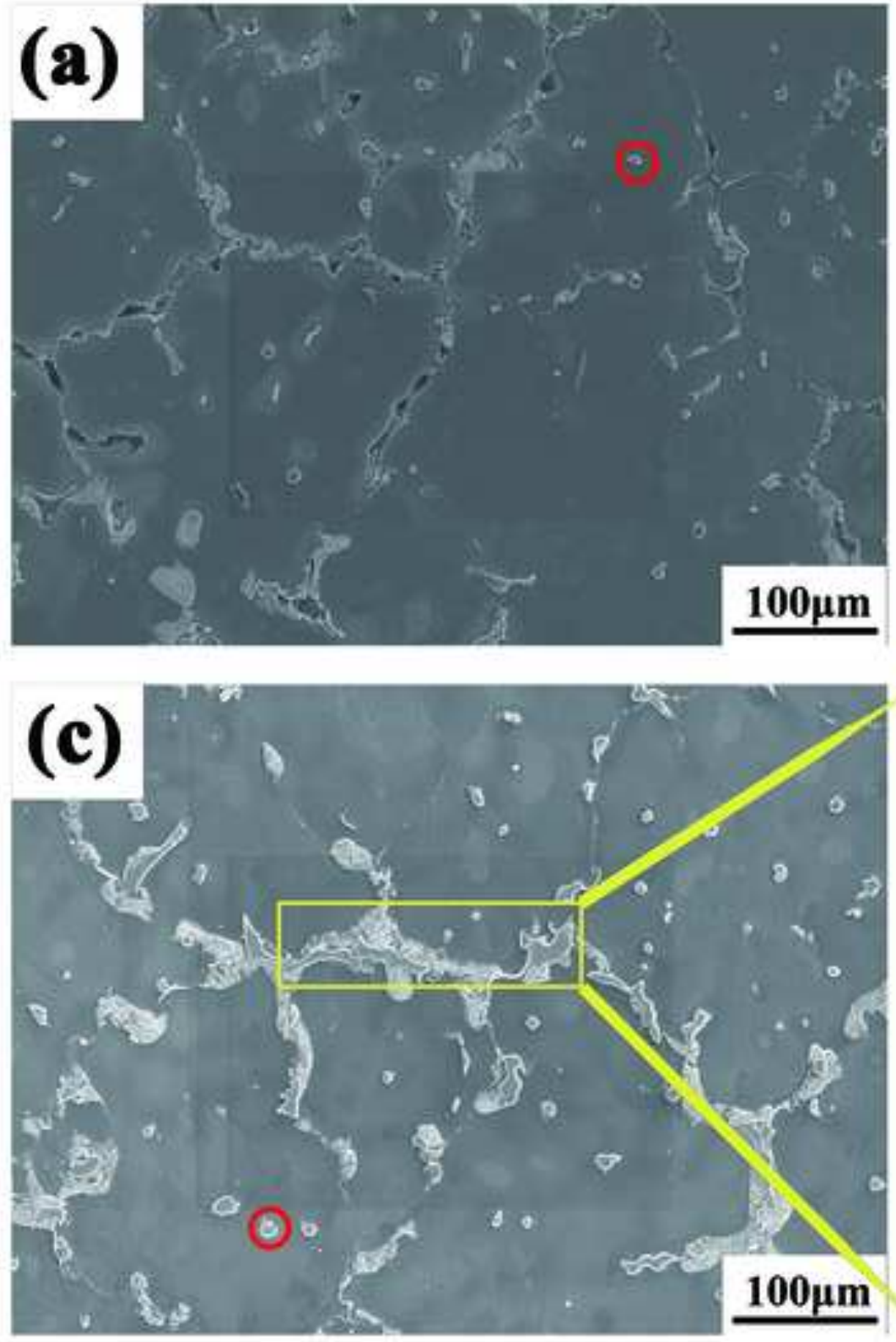

(b)

12:3

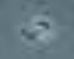

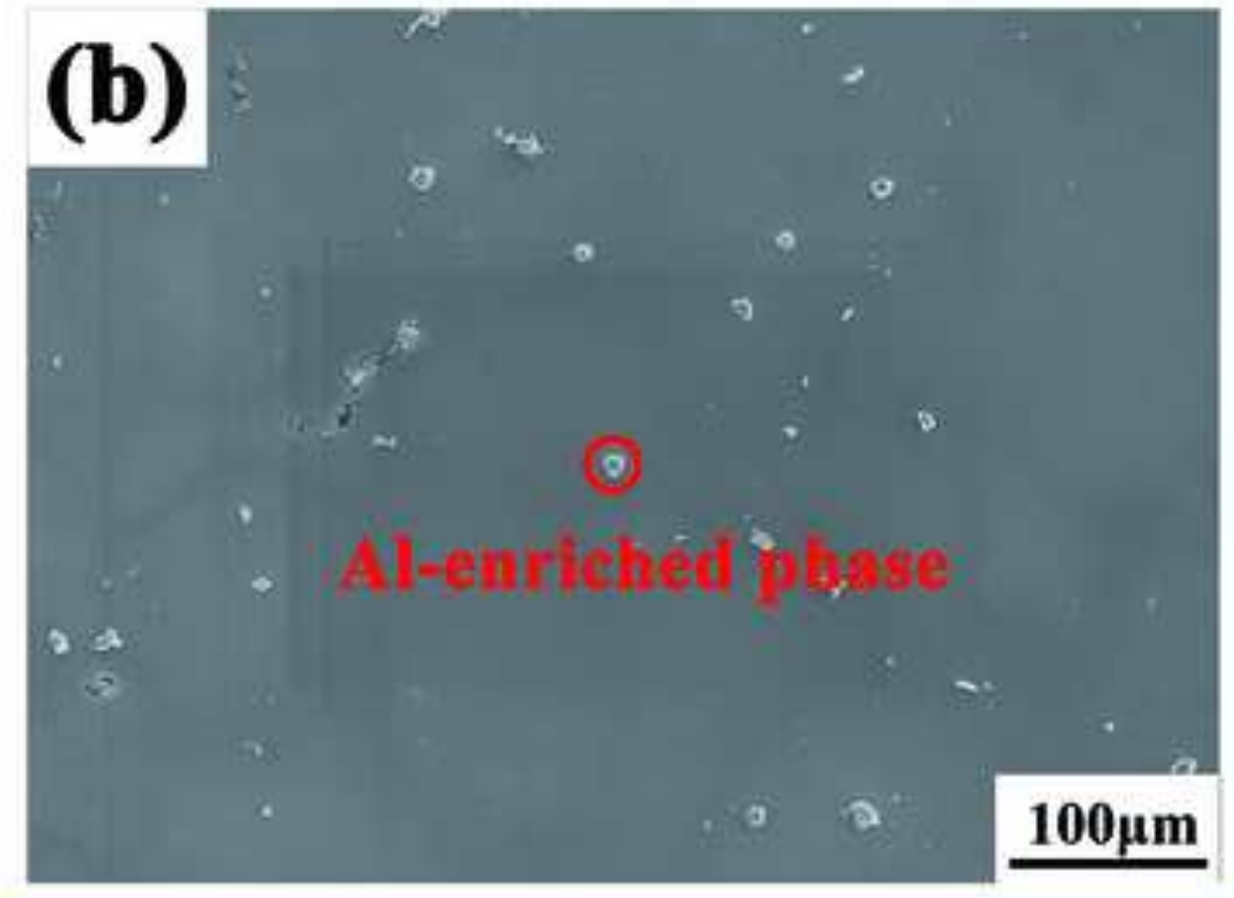

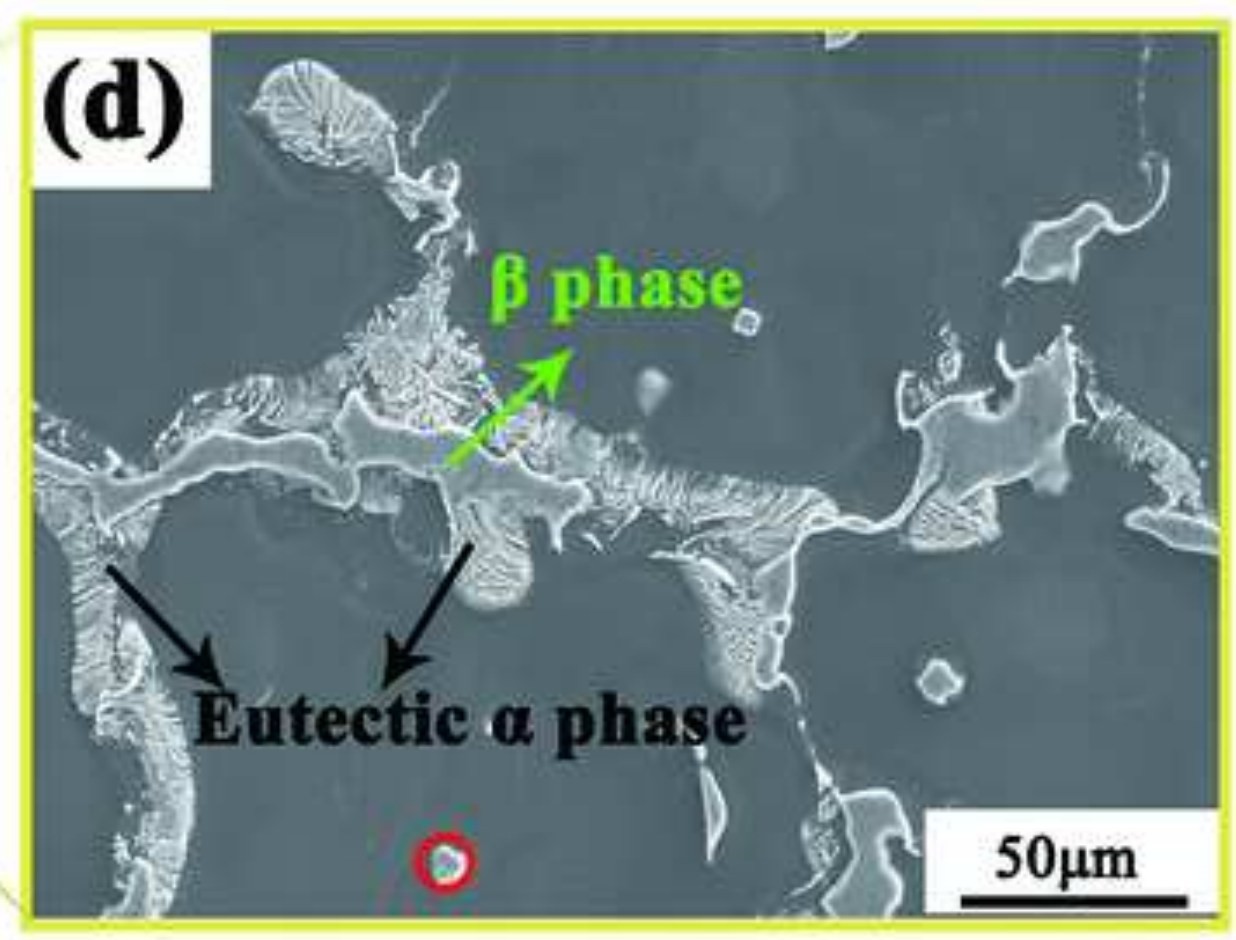



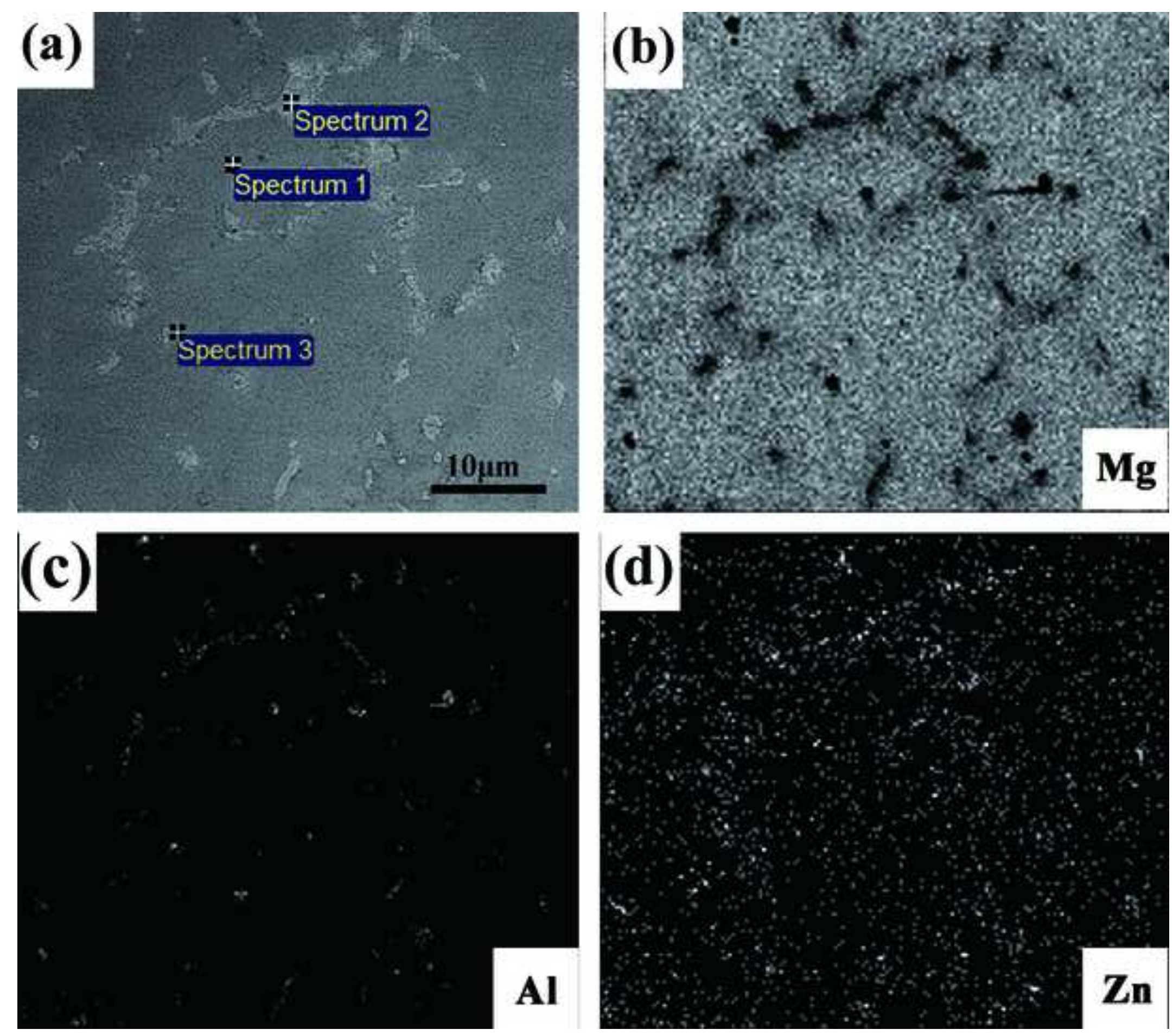

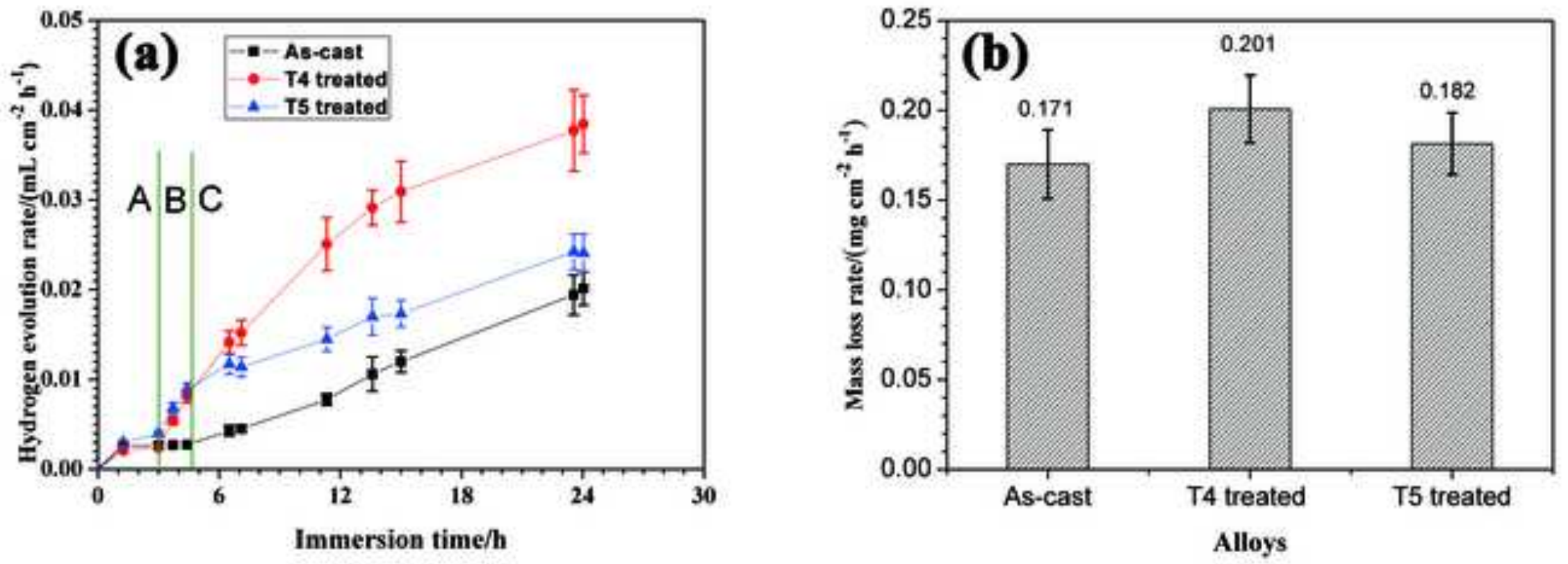

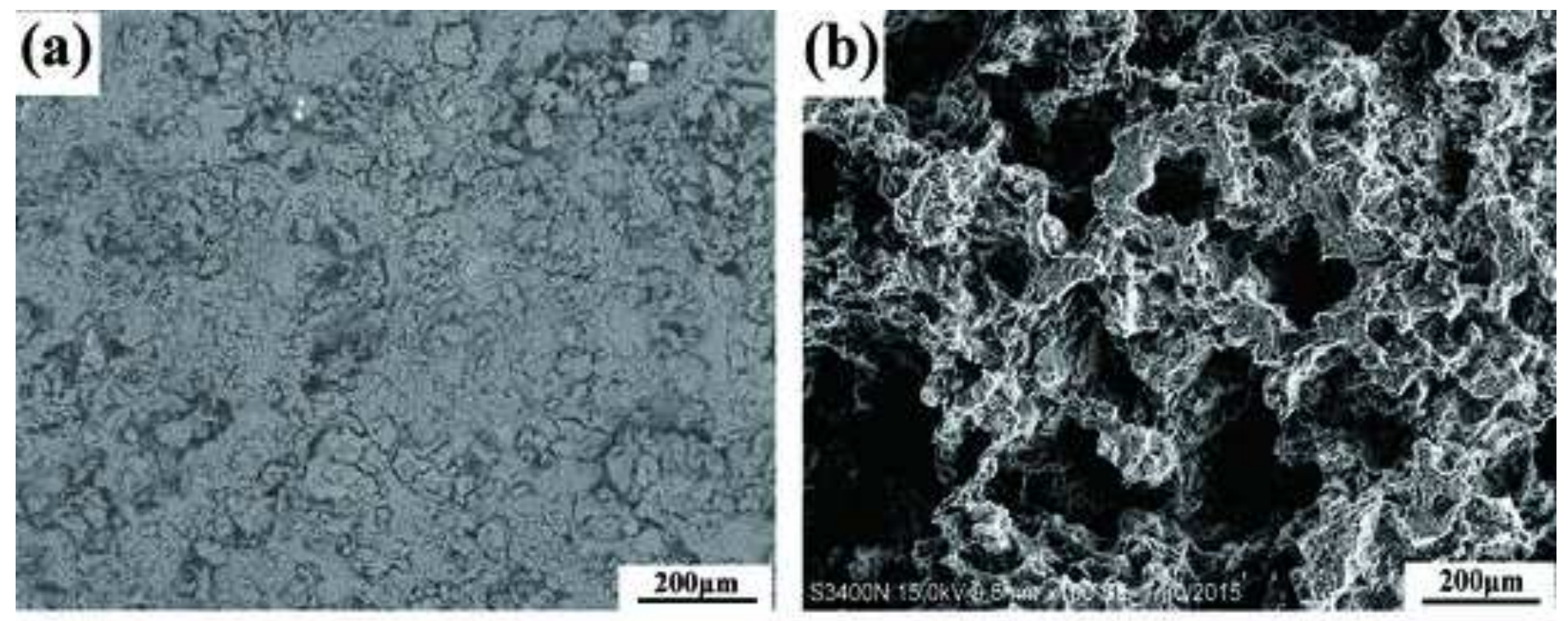

\section{(c)}

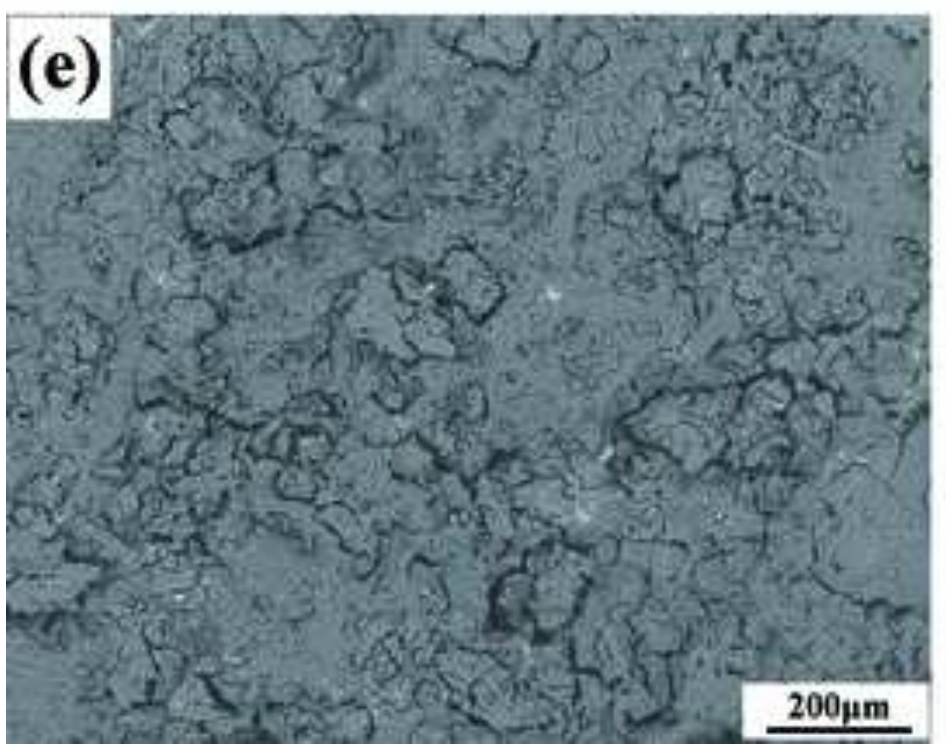

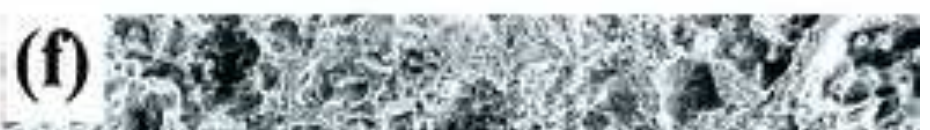

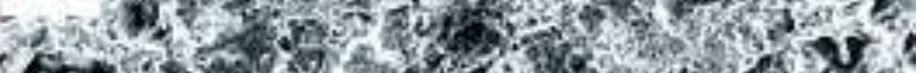
on $0^{2}$.

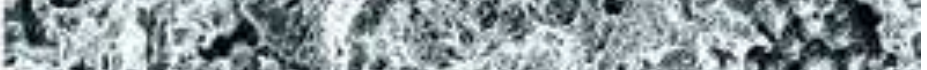

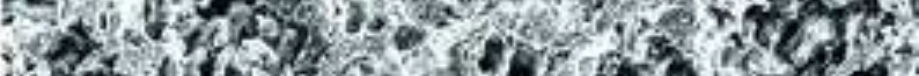
H. 3 3.

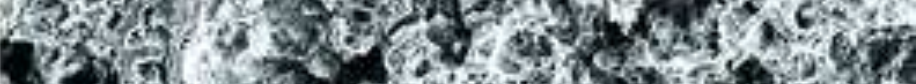
310 mons

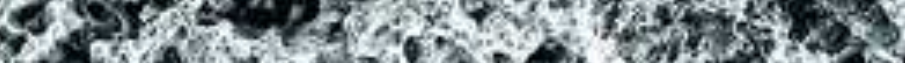

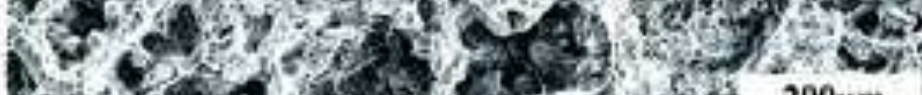
4y 104 f 


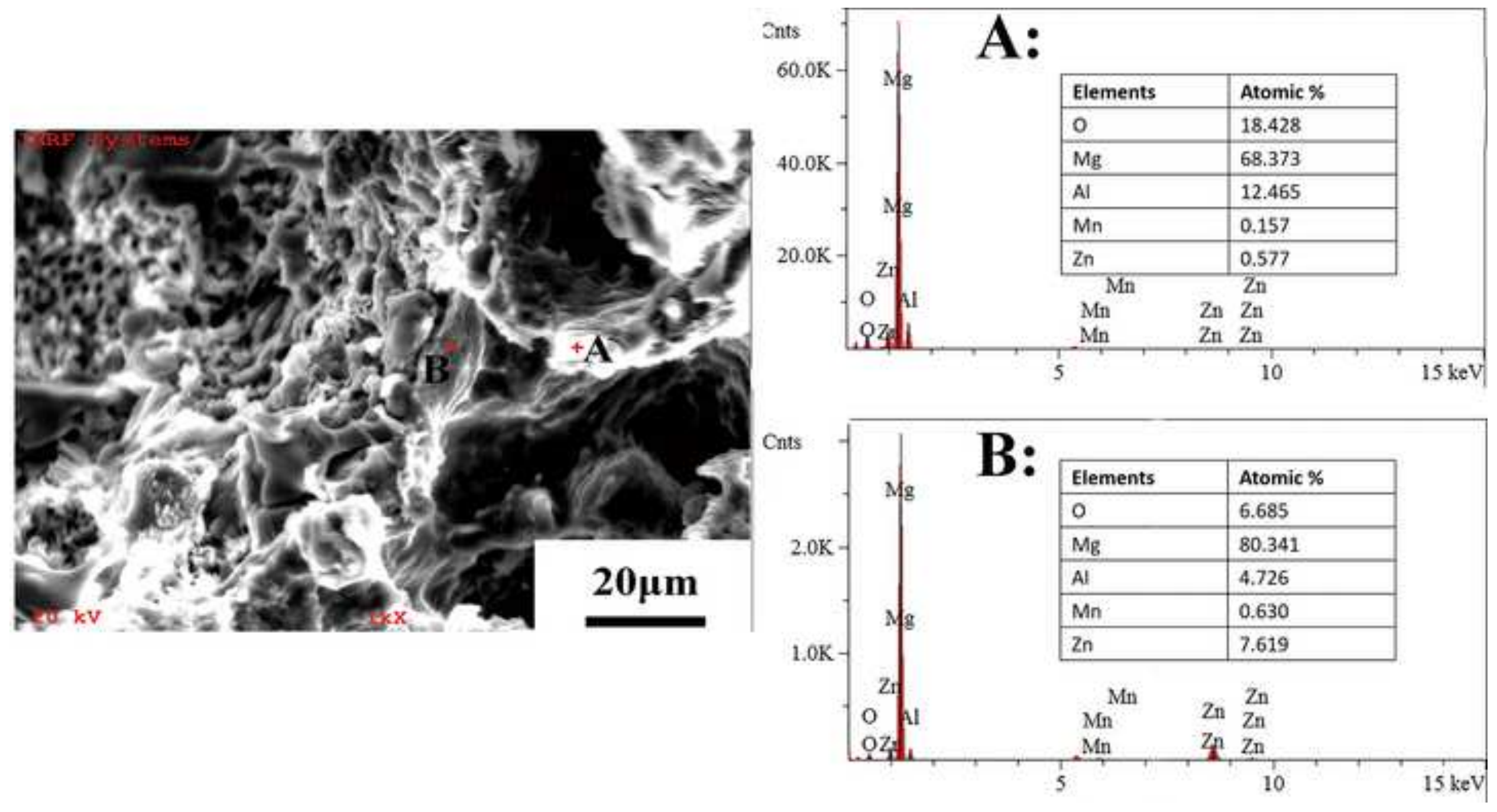



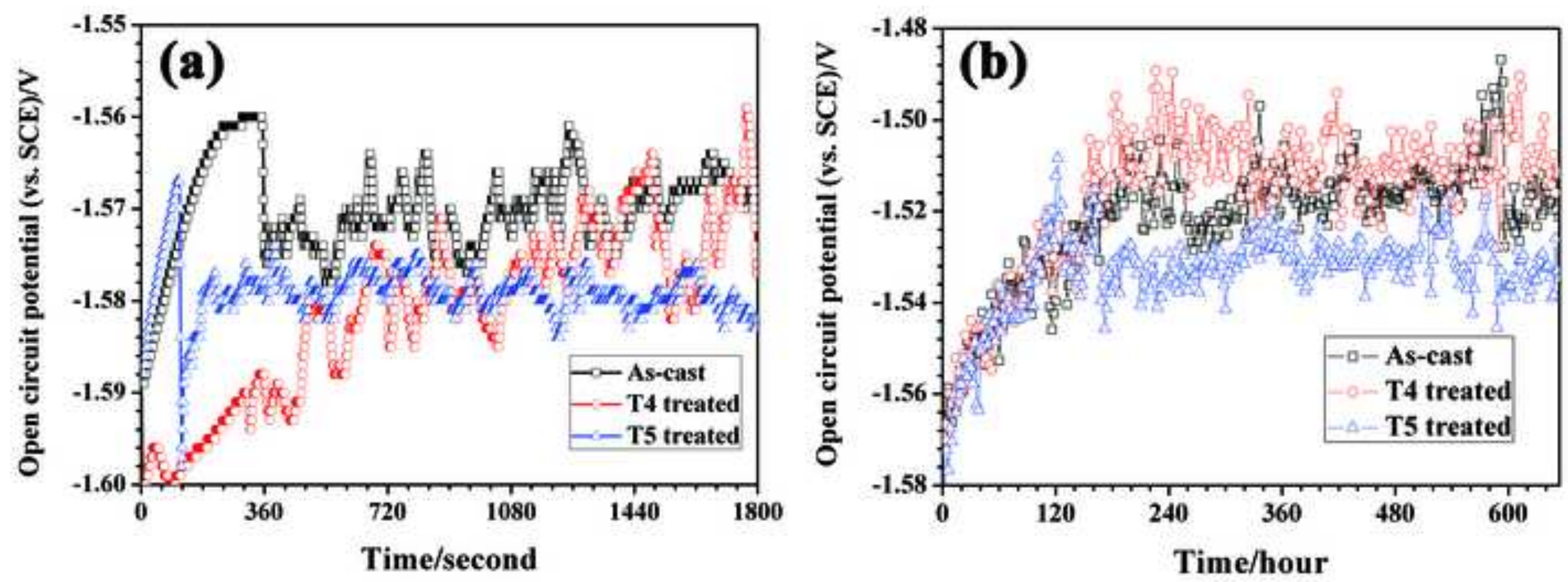


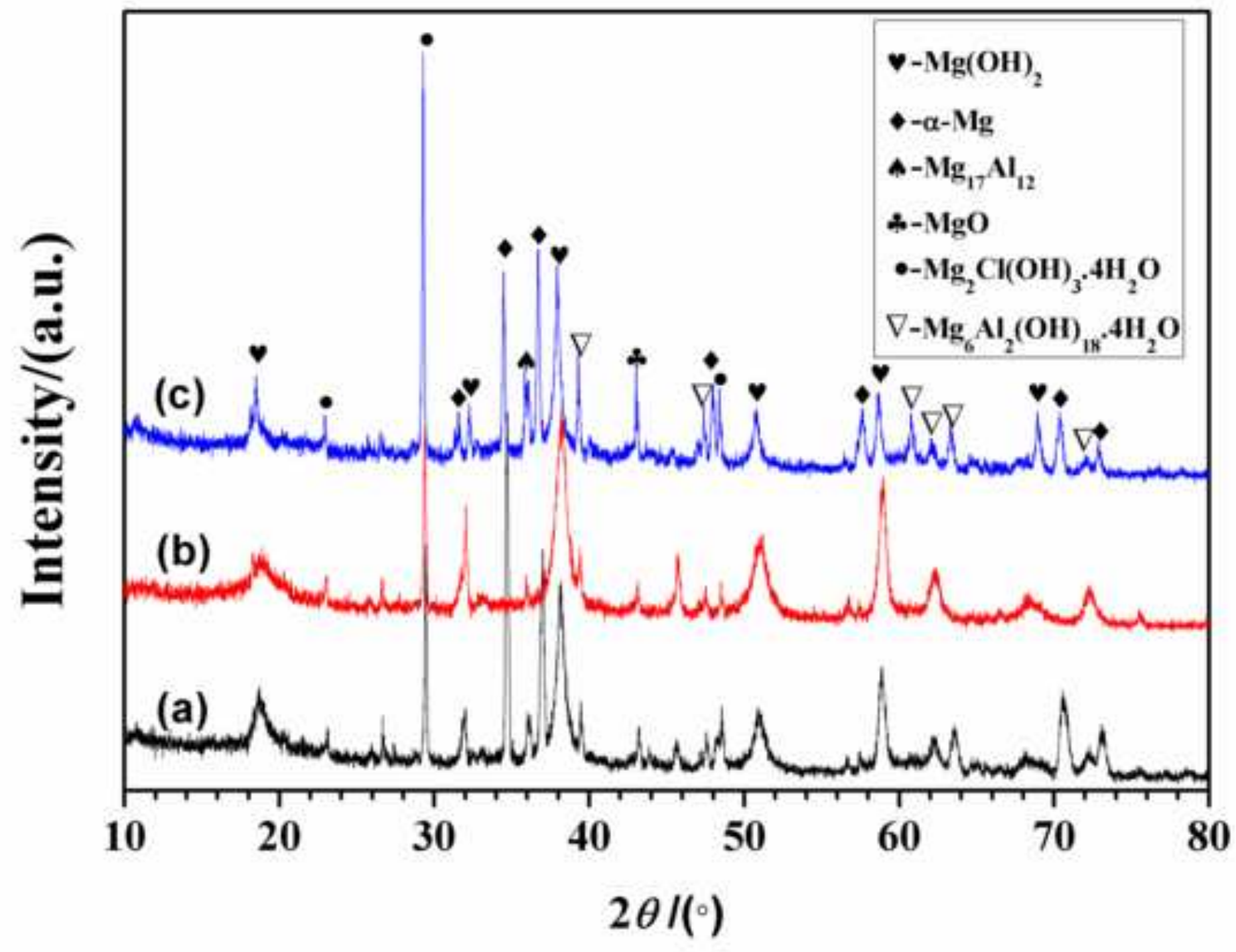




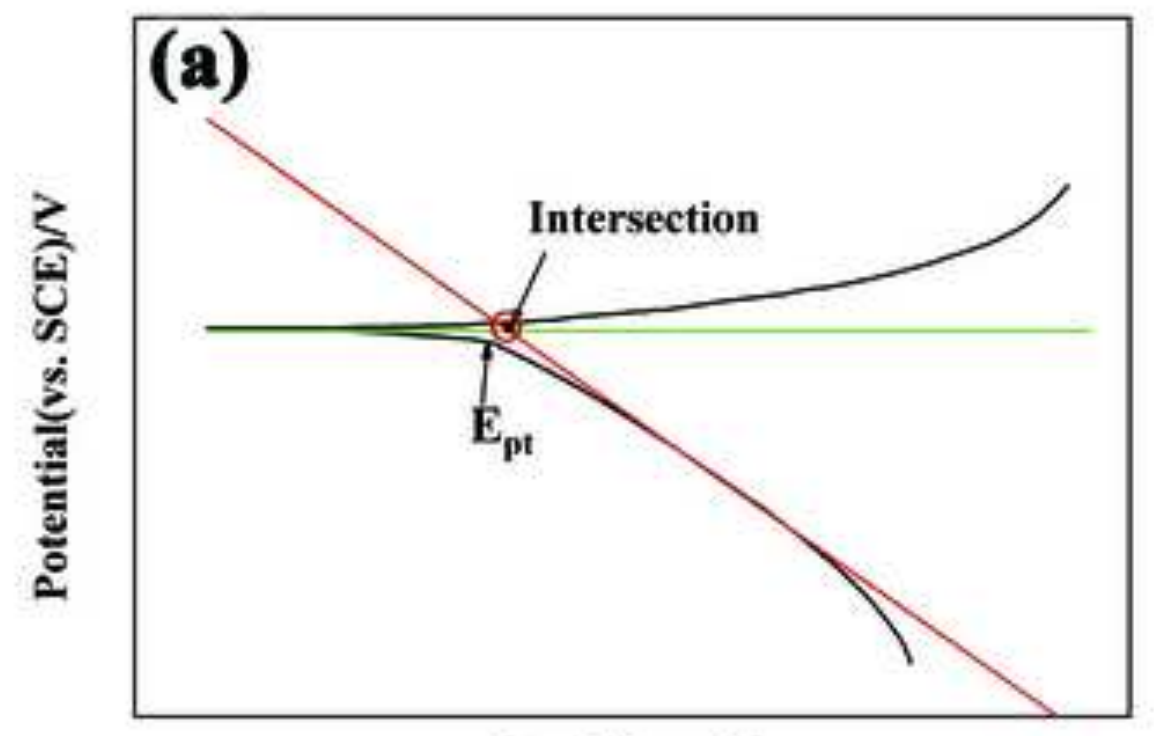

$\log _{\left(i / A ~ ~ c m^{-2}\right)}$
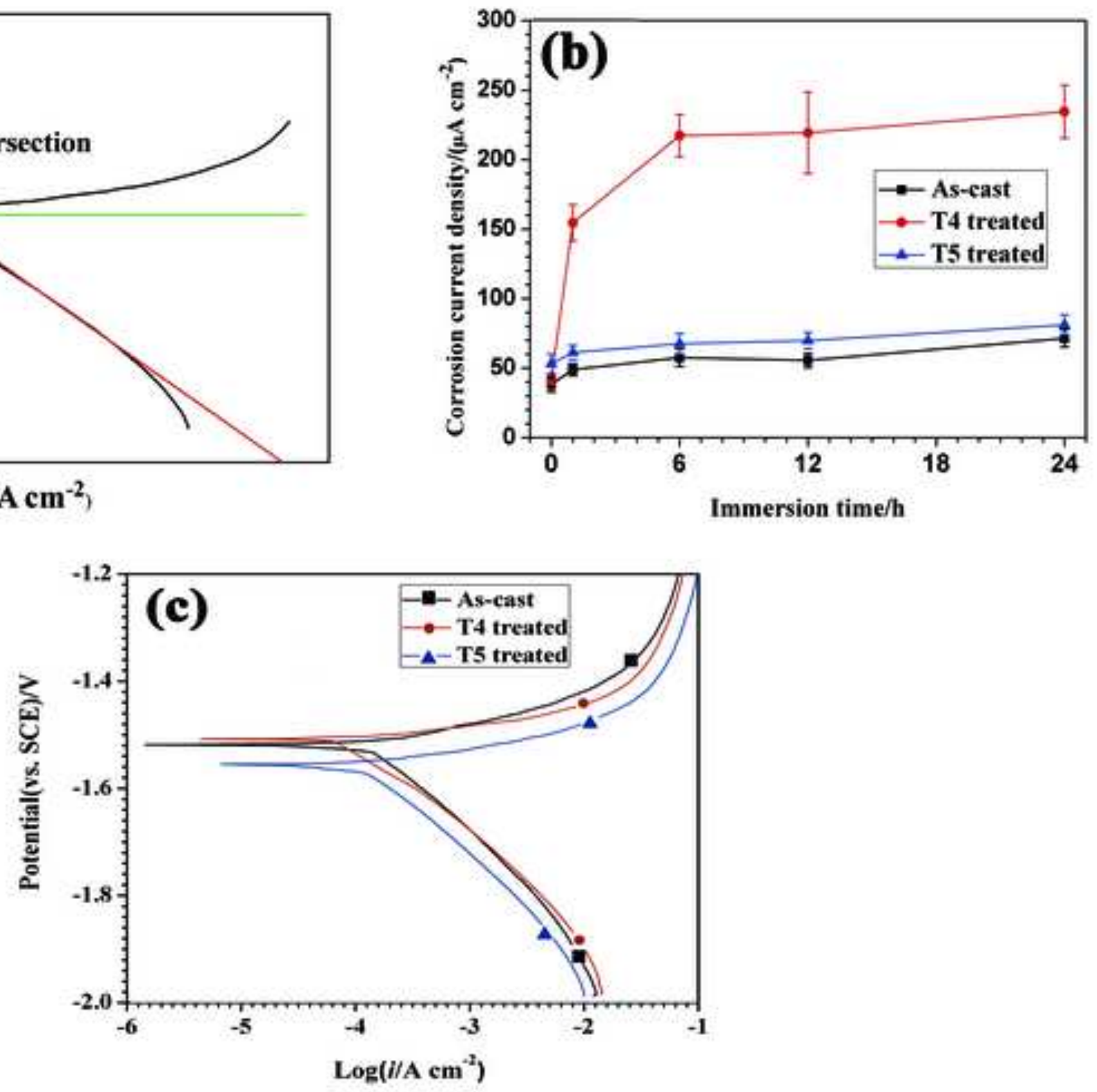

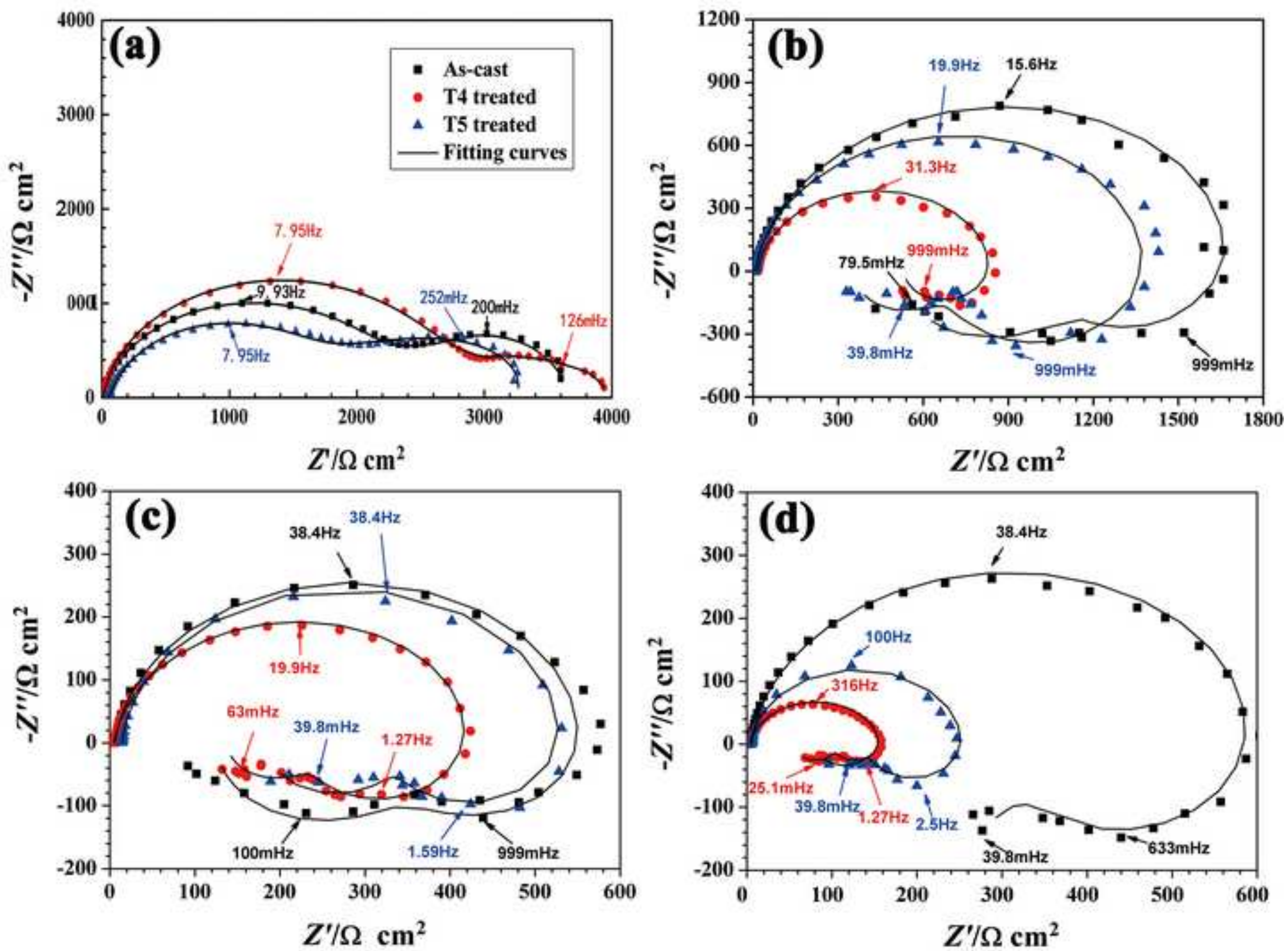
(a)

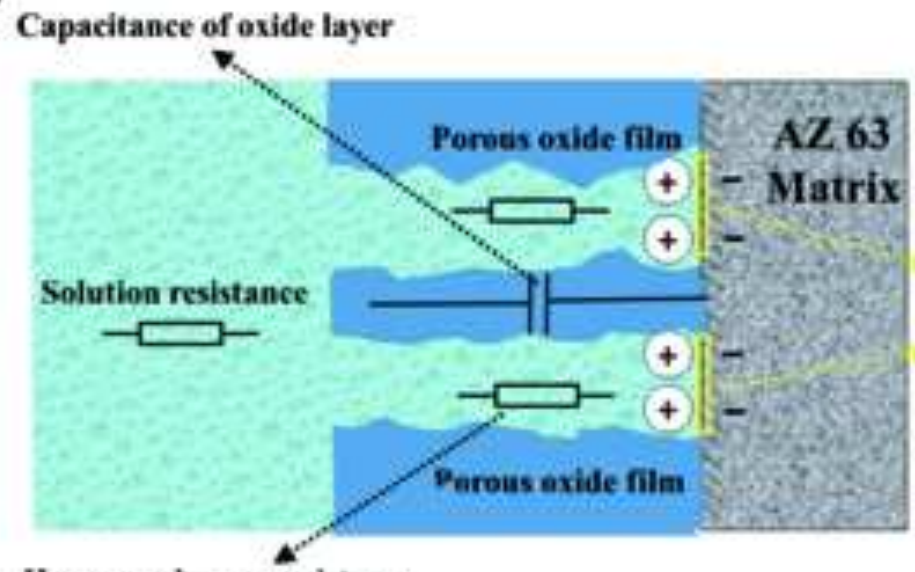

Honeycomb pore resistance
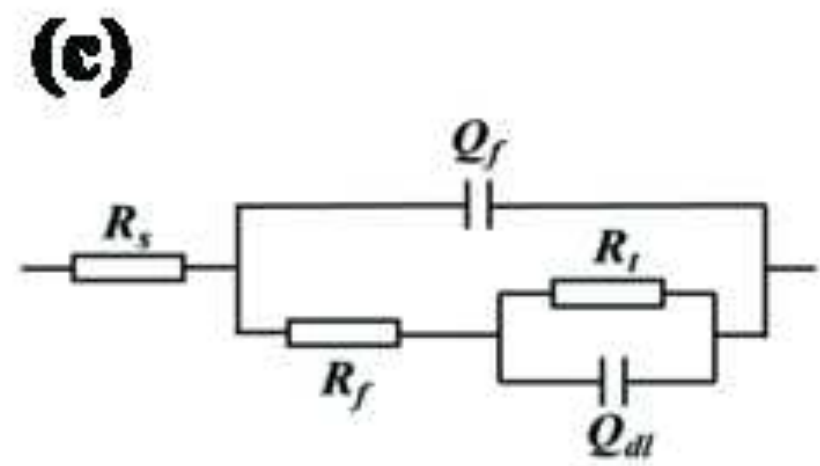

(b)

Corrosion products desorption
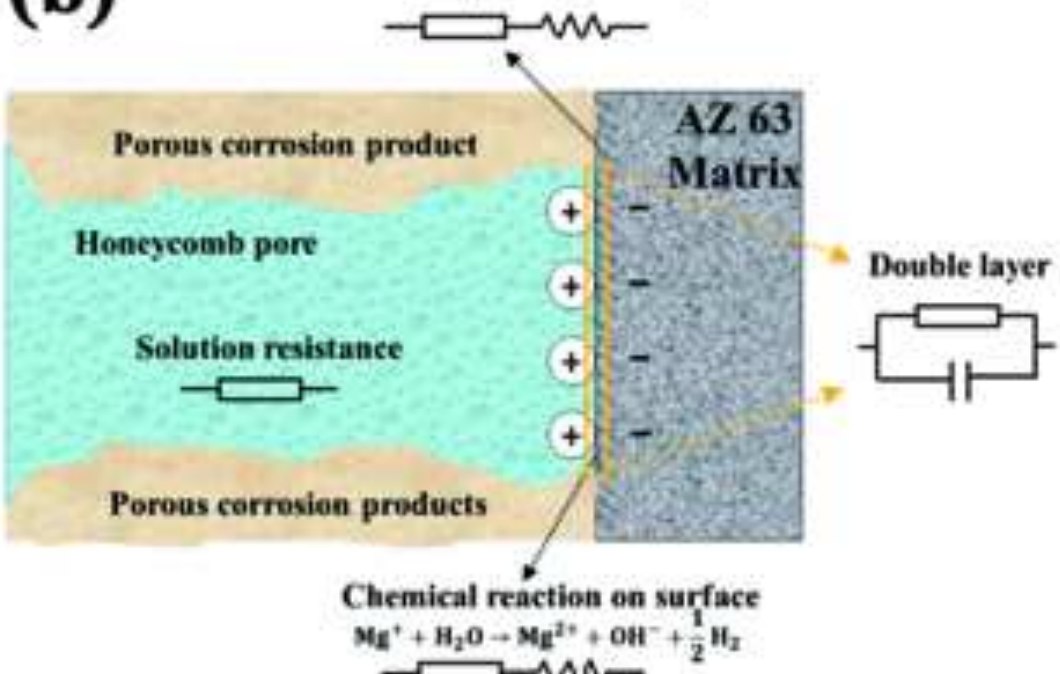

(d)
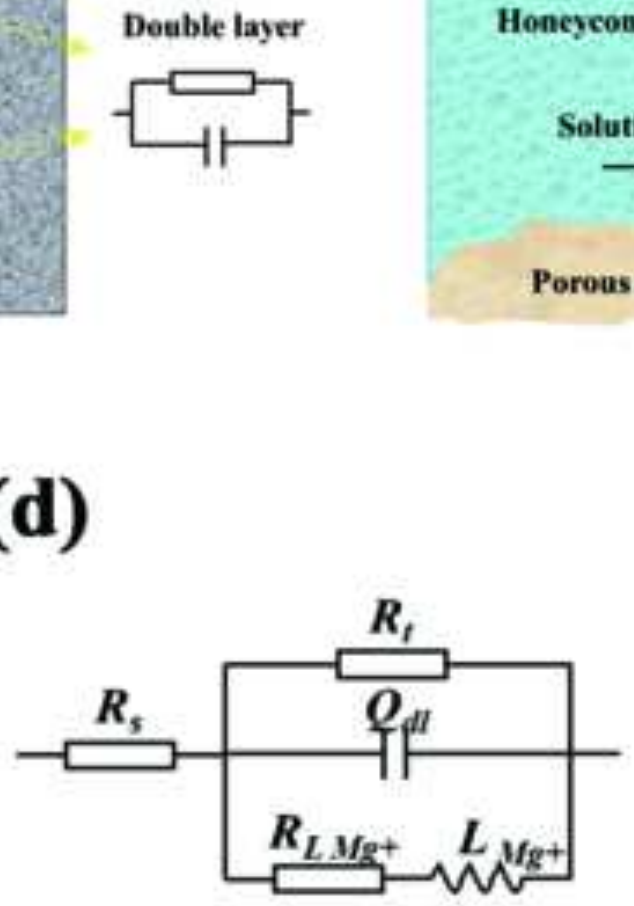

(e)

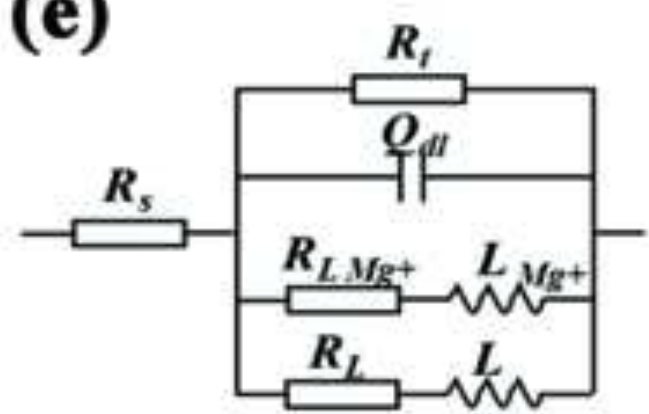




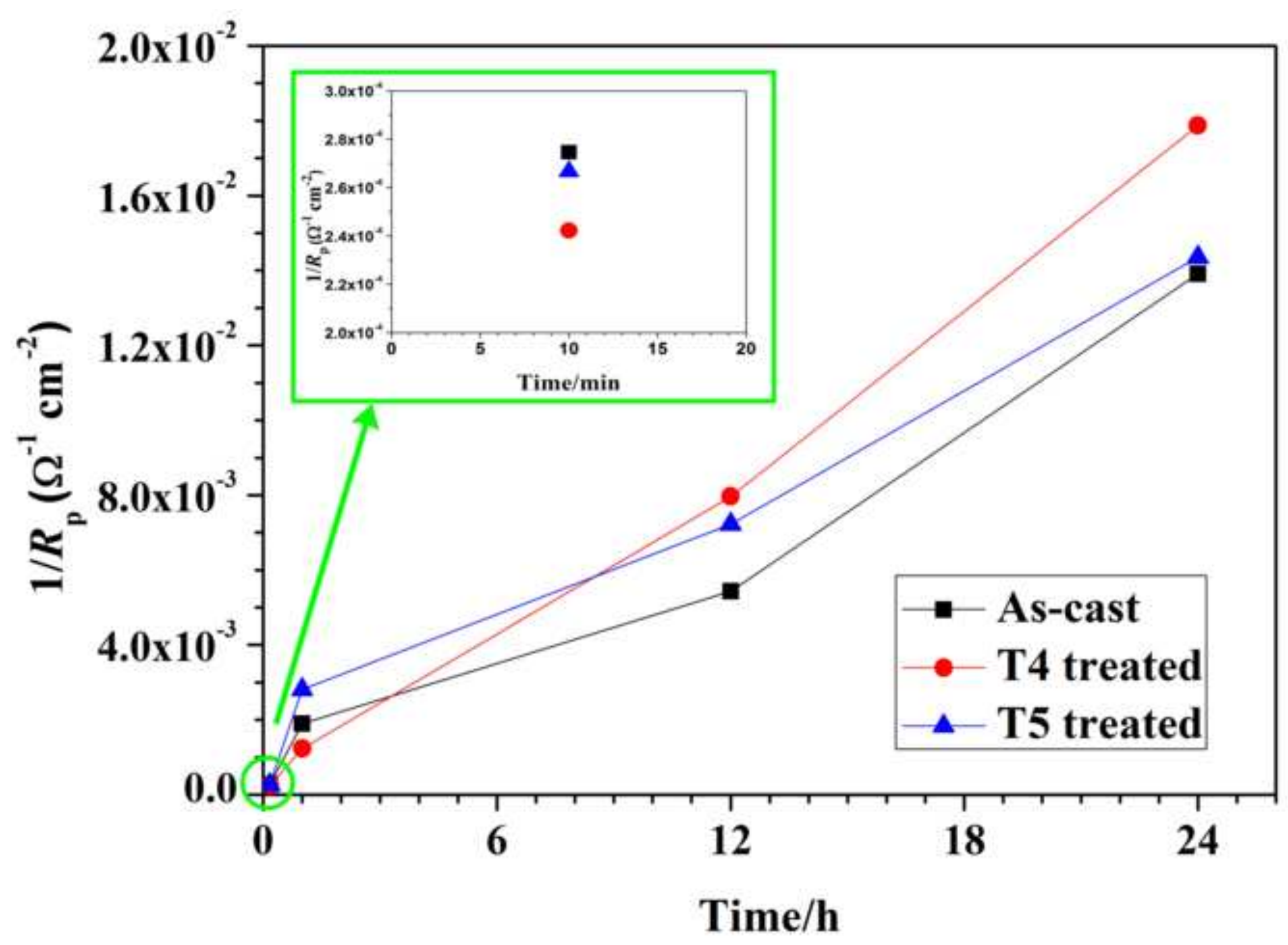

Time/h 

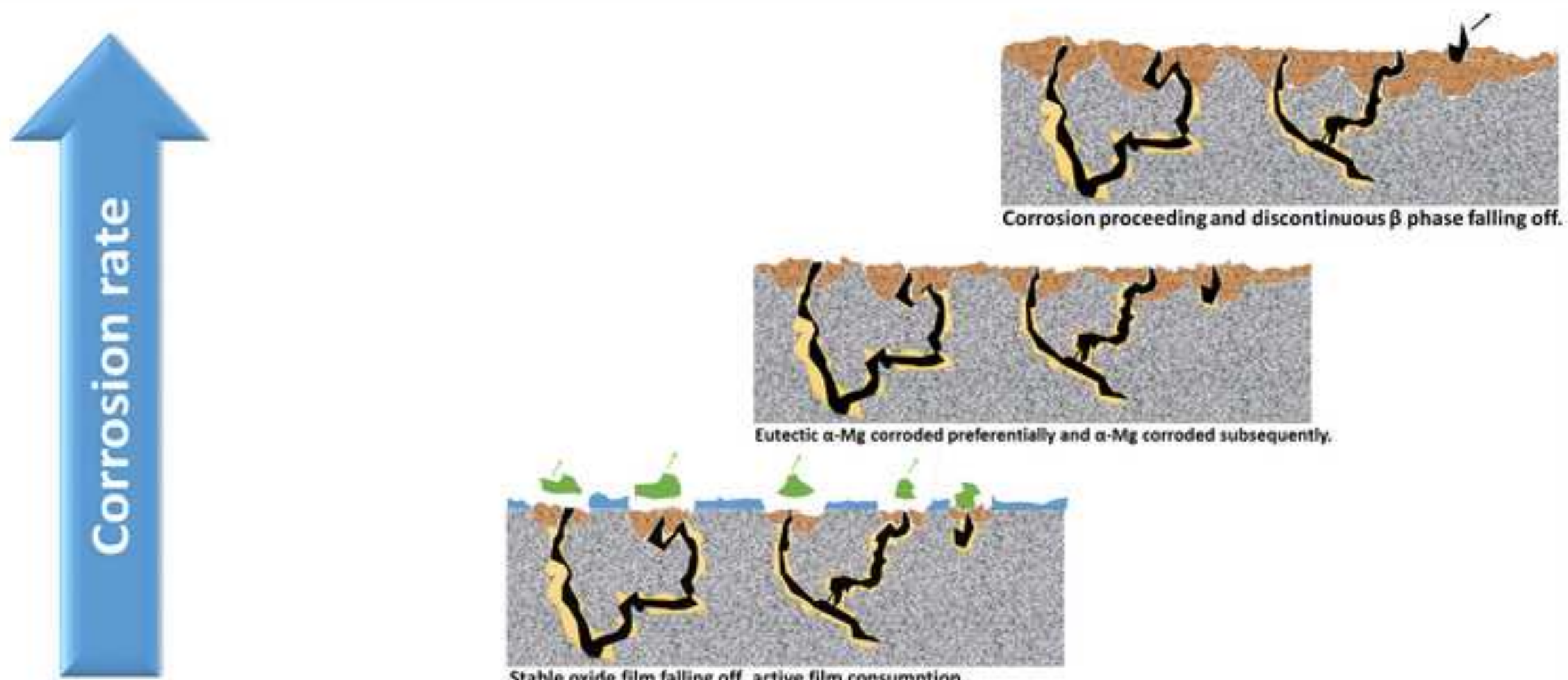

Eutectic a-Mg corroded preferentially and $\alpha \cdot \mathrm{Mg}_{\mathrm{g}}$ corroded subsequently.

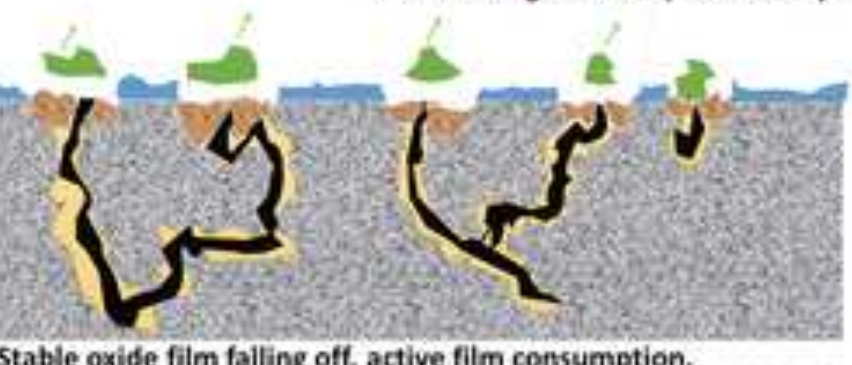

Stable oxide film falling off, active film consumption.

Corrosion products

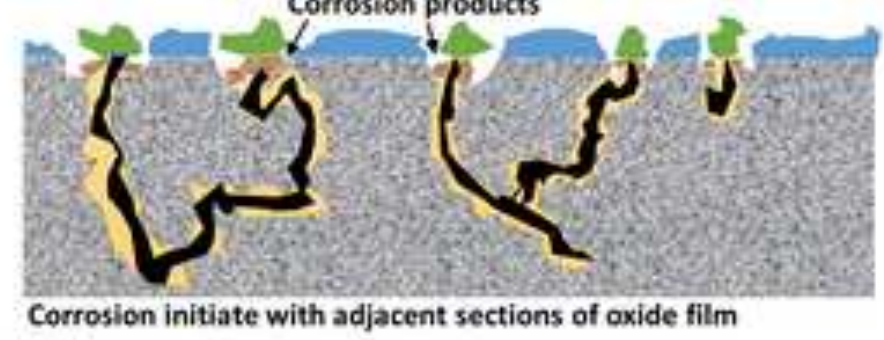

Oxide film (stable section) Oxidefilm (active section)

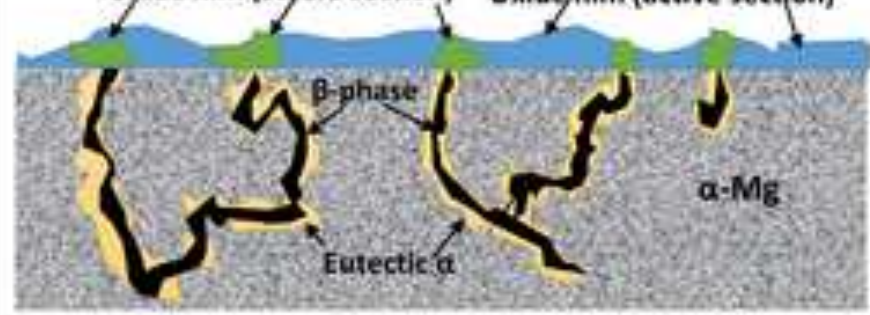

\section{Immersion time}




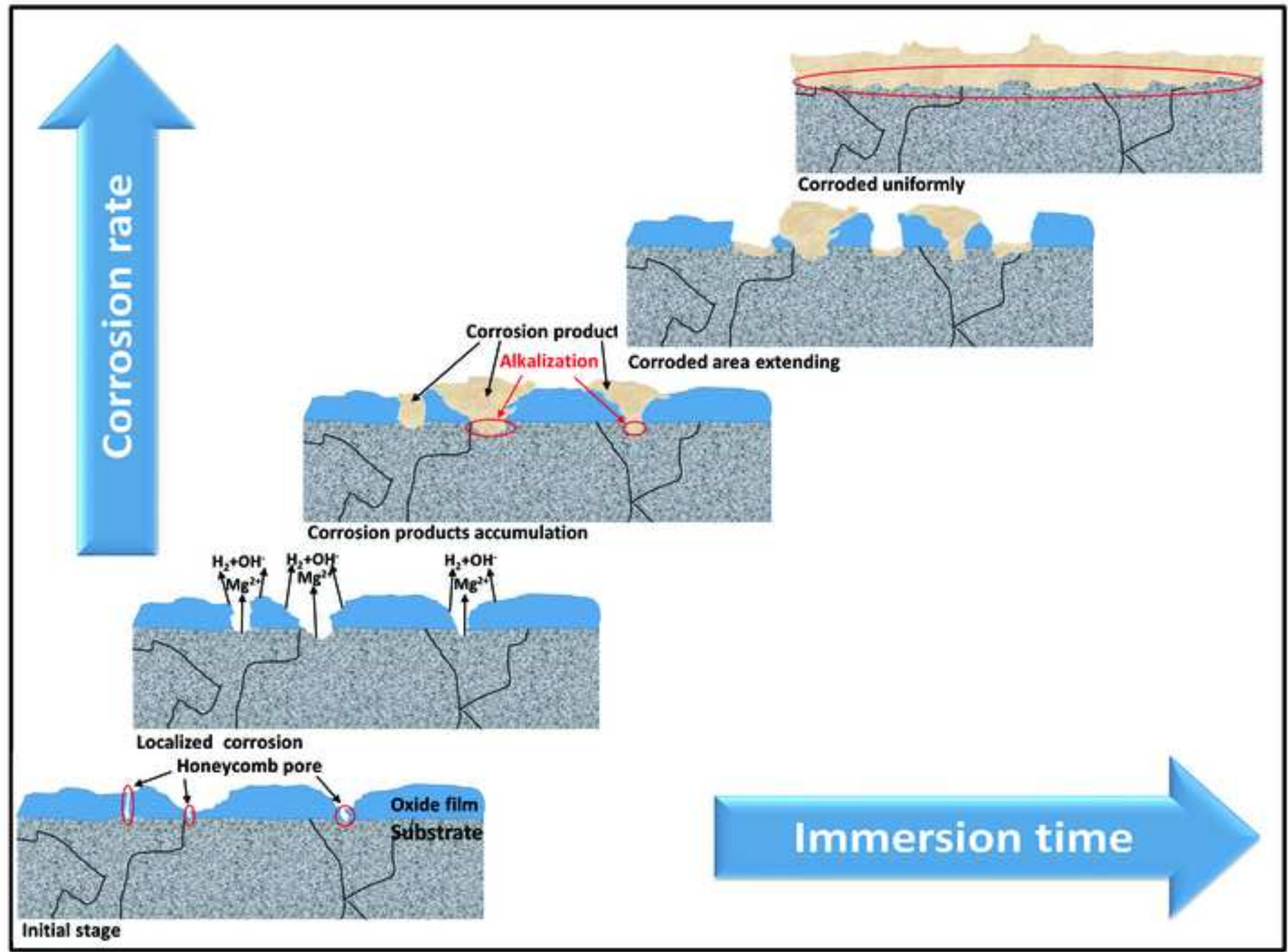


